\title{
Towards a Stronger Simulation Support for Engine Control Design: a Methodological Point of View
}

\author{
A. Albrecht, O. Grondin, F. Le Berr and G. Le Solliec \\ Institut français du pétrole, IFP, 1-4, avenue de Bois-Préau, 92852 Rueil-Malmaison Cedex - France \\ e-mail: antoine.albrech+@ifp.fr - olivier.grondin@ifp.fr - fabrice.le-berr@ifp.fr - guenael.le-solliec@ifp.fr
}

\begin{abstract}
Résumé - Vers un support plus fort de la simulation pour la conception du contrôle moteur : un point de vue méthodologique - Grâce à une modélisation fine et à une mise au point méthodique des simulateurs, il est aujourd'hui possible de concevoir un simulateur complet. Ce simulateur constitue un outil d'aide efficace pour l'ingénieur contrôle moteur dans sa démarche de conception, en donnant accès à de nombreuses informations parfois difficiles à mesurer expérimentalement, et en offrant la possibilité de réaliser facilement un grand nombre de tests sur une large plage de fonctionnement. Développé dans un environnement cohérent, le simulateur moteur peut accompagner de façon adaptée la mise au point du contrôle dans toutes les étapes du cycle de conception. Cette utilisation s'initie par la compréhension fine des dynamiques du moteur et peut être poursuivie jusqu'à la pré-calibration du contrôle sur simulateur temps réel.
\end{abstract}

\footnotetext{
Abstract - Towards a Stronger Simulation Support for Engine Control Design: a Methodological Point of View - Thanks to a specific crank angle degree modelling approach and to an accurate simulator calibration, it is nowadays possible to build a complete simulator which allows the control engineer to access to numerous engine variables, especially non measurable values, and to perform tests over a wide range of operating conditions. Hosted in a dedicated platform, the engine simulator can support the control system design at each stage of the development cycle. Its use starts with the local dynamics understanding of the engine behaviour and ends with the real time control pre-calibration.
} 


\section{DEFINITIONS, ACRONYMS, ABBREVIATIONS}

$\begin{array}{ll}\text { AFR } & \text { Air Fuel Ratio } \\ \text { ANN } & \text { Artificial Neural Network } \\ \text { AMT } & \text { Automated Manual Transmission } \\ \text { BGR } & \text { Burnt Gas Ratio } \\ \text { CFD } & \text { Computational Fluid Dynamics } \\ \text { CNG } & \text { Compressed Natural Gas } \\ \text { DI } & \text { Direct Injection } \\ \text { ECU } & \text { Electronic Control Unit } \\ \text { EGR } & \text { Exhaust Gas Recirculation (vane) } \\ \text { HCCI } & \text { Homogeneous Charge Compression Ignition } \\ \text { HiL } & \text { Hardware in the Loop } \\ \text { MVEM Mean Value Engine Model } \\ \text { NADI } & \text { Narrow Angle Direct Injection } \\ \text { NOx } & \text { Nitric Oxydes } \\ \text { SI } & \text { Spark Ignition } \\ \text { SISO } & \text { Single Input Single Output } \\ \text { TDC } & \text { Top Dead Center } \\ \text { VGT } & \text { Variable Geometry Turbocharger }\end{array}$

\section{INTRODUCTION}

The current issues for control design of new engine technologies are becoming more and more challenging since the number of actuators to be managed is growing. In this context, the control targets are becoming more difficult to reach. To adapt the control development methodology according to these new constraints is therefore an important item. For this purpose, the engine and vehicle simulation is a very effective way to reduce or anticipate the experimental tests. As a matter of fact, it offers a low cost and relevant support for engine control design.

In this contribution, the authors propose to present a generic methodology for control design with an intensive use of engine and vehicle simulators. At first, the paper will describe a modelling development process based on continuous approach. This first part is twofold: a general presentation and the specific case of combustion modelling. In a second part, a methodological point of view of simulator design is presented. It describes the main aspects of this issue : tool, simulator building, calibration and validation. The last part is dedicated to the control design methodology using simulation. After a description of the general philosophy, gasoline, natural gas and Diesel application examples are presented for the main control items such as air and fuel path control or vehicle calibration issues. According to the specific control goals, three simulator versions are used : the reference simulator, the fixed-step simulator and the real time simulator $[1,2]$.

\section{MODELLING DEVELOPMENT THROUGH A CONTINUOUS APPROACH}

\subsection{Standard Modelling Levels for Engine Simulation}

Mainly three types of modelling levels are used for engine simulation. The most accurate modelling approach is the CFD 2D/3D simulation. It is dedicated to local studies as the combustion chamber simulation which permits to finely capture the small scale in-cylinder phenomena such as turbulent combustion and chemical kinetics. The characteristic timescale of CFD simulation is to the order of the turbulent timescale. At the present time, the CPU time of such a simulation only allows to run a few engine cycles. The simplest modelling approach consists in representing the engine with operating condition look-up tables. This level achieves CPU time lower than real time and is used to run standard driving cycle with a low dynamic vehicle simulator. The characteristic timescale of vehicle simulation is to the order of $0.1 \mathrm{sec}-$ ond. At a turning point between these two approaches, the third modelling level is the engine system modelling. This approach involves phenomenological or empirical models and allows representing the complete engine with a characteristic timescale to the order of 0.1 crankshaft degree. Thanks to a dedicated code optimisation to limit the CPU time cost, the engine system model allows to reproduce accurately the behaviour of the engine during transients such as driving cycles while reaching the real time in certain conditions. Therefore, this approach is well adapted to be used as a support tool for engine control design from the control development to the hardware-in-the-loop validation [3].

\subsection{From 3D to Look Up Table Models}

The simulation has a high potential to become progressively an efficient tool for control purpose. However, it will be an indisputable standard in the control design process if the way the modelling is developed allows building solid and coherent approaches. To face the challenges of dealing with the increasing complexity of engines and powertrains, the control has very high expectations from modelling accuracy. For example, the current HCCI engine control design must take into account phenomena very hard to model such as combustion with high exhaust gas recirculation rate, noise and pollutant production or cylinder to cylinder disparity.

From a simple point of view, the models developed for engine simulation can be organised on a physical modelling level axis, from 3D to look up table models. Most of the time, a gain of predictive capability is obtained by increasing the model complexity and so, the CPU cost. In this context, it is easy to understand that a modelling roadmap focused on a specific level of this axis does not give the adapted environment to improve the general physical accuracy and maintain 
low CPU cost models. The modelling development through a continuous process is an interesting solution to have a solid modelling approach which takes its roots in the 3D modelling and is based on a coherent chain from reference 1D/0D models to look up table models (Fig. 1).

For each modelling stage, the main advantages of such a development process are:

- to take benefit from a coherent framework thanks to the up-level models which are used as modelling guideline,

- to have an access to detailed variables from the most accurate models to facilitate the refined validation of the new developments,

- to offer an efficient validation tool which allows to obtain the reference results with more flexibility than with experimental test bed.

As represented on Figure 1, the experimental results are still required for a complete model design but can more easily be used at a later stage of model development.

The next section describes with more details how this continuous approach can be applied with the crucial case of the combustion modelling.

\subsection{Combustion Modelling}

The 2D/3D combustion modelling is one of the major current engine research areas with an intensive production. Among recent publications, one can mention [4-7]. Thanks to this reference modelling level, most of the local mechanisms such as auto-ignition, pollutant production or turbulent mixing, that a $0 \mathrm{D}$ combustion model is supposed to represent, are available. Moreover, a 2D/3D simulation code can also be used for a posteriori testing during OD model development. It consists in testing the OD model in the $3 \mathrm{D}$ code applying an average operator on the $3 \mathrm{D}$ results to assess the $0 \mathrm{D}$ approach relevance in a first level. Finally, based on the Navier-Stokes equations, the $2 \mathrm{D} / 3 \mathrm{D}$ modelling has to settle specific techniques especially to represent sub-grid phenomena such as moment closure equations or probability density functions. To adapt some of these approaches to OD modelling gives a very promising framework to improve the physical performance of the $0 \mathrm{D}$ combustion model with reduced CPU increase [8].

The $1 \mathrm{D}$ and multi-zone modelling is also currently widely investigated [9-13]. It allows to represent the in-cylinder heterogeneities involved in the local combustion and pollutant production terms which cannot be achieved with OD modelling. These models are based on various techniques of combustion chamber sharing according to Eulerian or Lagrangian considerations. These models are a very interesting stage between the 3D and the OD modelling to investigate the modelling reduction approaches and to be used as a reference. However their characteristic CPU time cost does not allow them to be directly used in a complete simulator, especially for control issues.

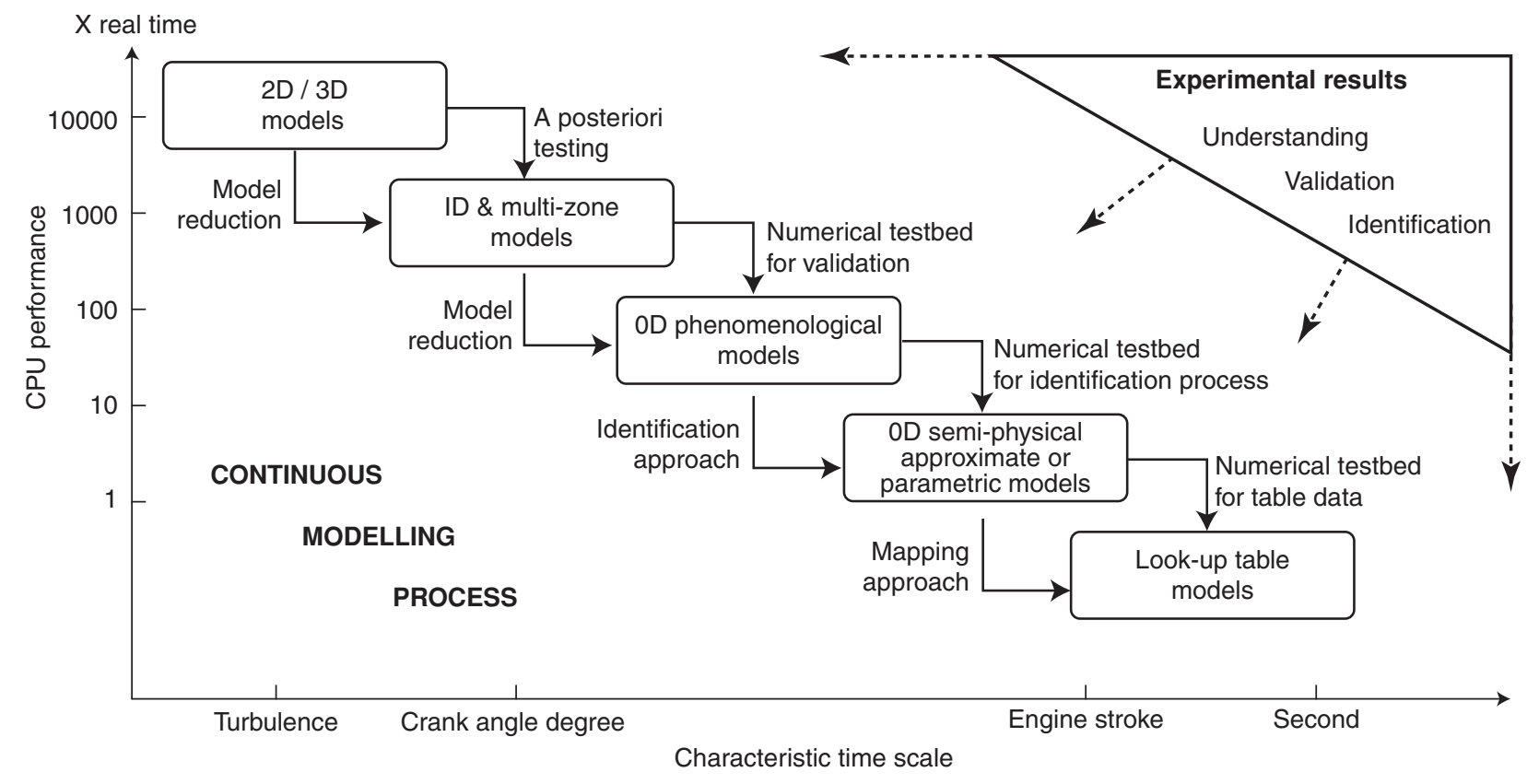

Figure 1

The continuous modelling process. 
The 0D phenomenological models are at the turning point of this modelling chain. It is the typical modelling level that has to extend its physical representative capability with reasonable CPU performance to be embedded in a full engine simulator as a reference version ( $c f$. Sect. 3.1 concerning the simulator versions). The well known pioneers of this kind of models for Diesel combustion are Barba and Burkhardt [14] and Chmela et al. $[15,16]$ but their contributions are mainly empirical and focused on specific applications. Therefore, they do not allow to directly face the complexity of the current challenges such as pollutant prediction, multi-injection strategy or high EGR combustion. These improvements may be achieved through a model complement as performed in [17] where an auto-ignition delay, the EGR effect and a cold flame model are added to the Chmela's basis to adapt it to HCCI combustion. Unfortunately, the empirical approach of these models limits their improvement potential and a modelling based on a more physical approach as proposed in [8] may be more promising to obtain low cost phenomenological models with extended performances in the long term. The spark ignition combustion is also concerned by the same goals $[18,19]$ with its own issues such as flame geometry or stratified combustion.

To be completely adapted to control design, the $0 \mathrm{D}$ combustion models are expected to have real time facilities. The previous combustion approach does not always fit with real time constraints. Therefore, specific models, based on a semi-physical approximate approach (also know as parametric models), are developed. For combustion, these models are focused on the values expected from the simulation. A dedicated identification process is then defined and applied on the results from an experimental or/and numerical combustion campaign (Wiebe [20] for combustion heat release under steady state conditions, [3] for cylinder pressure under transient conditions).

Finally, if the requirements are adapted, the look up table models can also be used as in a mean value engine model for control items focused on lower dynamics issues.

Since anyone of these modelling levels is adapted to answer alone to all the control expectations in terms of physical accuracy, working conditions and CPU performance at the present time, to set up a continuous model chain as complete as possible is an attractive way to improve the model capabilities with coherence and to provide a set of relevant solutions for control applications.

\section{SIMULATOR DESIGN AND CALIBRATION}

This part presents a methodological point of view for the main aspects involved in the simulator design and calibration: the simulation tool environment, the building, the calibration and the validation of the simulator.

\subsection{Simulation Tool Environment}

One crucial aspect that has to be imperatively considered to take benefits of the methodological point of view presented in this paper is the simulation tool environment. Working in an appropriate modelling and simulation software environment is one of the main success factor for the simulation to become a key support for control purposes. The next sections describe the relevant properties for the simulation tool environment for such a goal. The IFP's choice to develop its libraries in the AMESim ${ }^{\circledR}$ edited by IMAGINE is based on these considerations.

\subsubsection{The Modelling Capitalization}

One major role of the modelling environment is to capitalize the model versions during its development. Nowadays, it is still usual to face difficulties in coding recovery and version multiplicity management. Therefore, it is important to perform the model development in the following framework:

- a standard and adapted coding language $(\mathrm{C}++$, Fortran, etc.),

- detailed coding instructions (organisation rules, systematic comments, etc.),

- a straight version management and traceability (library organisation, update integration process, version validation protocol, etc.).

Some of these aspects may be directly addressed in the software development quality process which is a very helpful way to give a standard to such an activity.

\subsubsection{The Platform Coherence}

Another fundamental issue is the platform coherence with the target application. Therefore, the way the simulation will be used has to be defined to limit the number of tools and simplify the integration in the application framework. For example, the control design application requires:

- a modelling approach which allows to take into account all the powertrain aspects and simulate multi-physics system (based on energetics transfers, the Bond Graph approach is a good candidate [21]),

- the ability to easily perform coupling between all the available models (such as pneumatic, hydraulic, thermal, mechanical and electrical aspects, for example [22]),

- the same environment for all the modelling levels and simulator versions to control efficiently all the simulation stages (such as model simplification, real time adaptations, etc.),

- adapted interface facilities with the others tools involved in the applications (Matlab/ SIMULINK, real time targets, etc.). 


\subsubsection{The Numerical Solver}

A third very important property to take into account for the simulation tool choice is the numerical performance. To be able to support all the control design expectations, the simulation software should provide:

- an efficient variable step numerical solver to capture accurately all the system dynamics (for example, the AMESim $^{\circledR}$ solver automatically switches between 17 schemes according to the system response stiffness),

- a fixed step solver to be able to significantly reduce the CPU time after all the relevant dynamics have been identified,

- adapted compilation facilities to match all the modelling and simulation requirements (debugging tool, code optimisation, real time compilation, model instrumentation, multi-processor computation, etc.).

\subsection{Simulator Set Up and Modelling Level}

During the whole process of simulator building, to take into account the simulator usage expectations is crucial to adopt a relevant modelling level.

The first important aspect of this usage context is the simulator application field. Indeed, the simulator design is not focused on the same topics if the simulator is intended to control design or to engine architecture design. The control design needs simulators calibrated on a very large amount of operating conditions to be representative of the real engine on the whole sphere of application. The engine architecture design is focused on the highly constrained operating conditions as the maximal torque and maximal power operating points.

The second important aspect is physical phenomena modelling adopted in the simulator. Depending on the application expectations, the simulator has to reach accuracy targets that have to be taken into account in the modelling level choice. At the present time, it is not possible to address all the performance targets in a single simulator. For instance, the air path control design needs simulators with an accurate modelling of the different components of the air circuit (the turbocharger, the EGR loop, the heat exchanger, etc.) but does not require to get an accurate simulator behaviour on the combustion process or pollutant emissions as it is the case for the combustion control issues. It is also difficult to take into account all these constraints in a single simulator version because of computational time considerations. This third aspect is crucial particularly for the control applications that need very fast simulator as Hardware-in-the-Loop (HiL) platforms which require simulators running in real time.

The final aspect to take into account during the simulator design stage is available data. Indeed, to build a sophisticated simulator when very few data are available is a non-sense because the calibration level will not be in agreement with the physical phenomena representation.
To achieve a relevant simulator, it is necessary to find the good compromise between these different aspects. It is often impossible to meet all these constraints in the same simulator what requires the design of several simulator versions. For instance, a first simulator version with accurate phenomenological models can be used to perform maps which may be integrated in a second simulator version dedicated to reduced computational time applications as represented on Figure 2.

\subsection{Simulator Calibration}

\subsubsection{General Methodology}

After the modelling set up stage, the simulator has to be calibrated on different operating conditions. This part conditions the simulator accuracy. Several methods could be applied to achieve this phase in a complete way. The global methodology is to try to separate the different component calibrations in order to limit the interactions which can induce mistakes. The ideal way consists in isolating the component to calibrate. With this approach, the model boundary conditions have to be imposed by the user. This method presents the advantage to not disturb the calibration with the component environment. Nevertheless, the application of this methodology to the whole engine is very time consuming and an accurate boundary condition determination is difficult for all the components. Furthermore, the experimental data necessary to an accurate calibration process are not always available.

An alternative is to successively calibrate the different components of the complete engine simulator by choosing operating conditions that minimize the component interactions. For instance, the calibration phase can be focused in a first time on the operating points with a closed EGR vane in order to minimise the interactions between the exhaust and the intake lines.

The calibration phase can be performed with an open or closed loop methodology. The open loop methodology is the most accurate and the most difficult one. It consists in imposing the bench actuator values on the simulator and to calibrate the different models to obtain the same test bed engine behaviour. The main difficulty of this method is that an actuator modelling defect may induce significant errors on the calibration. The closed loop method consists in imposing important and controllable variables like the intake pressure and the air equivalence ratio by an appropriate actuator regulation. The actuator modelling defects do not induce error any more and the component calibration becomes easier. Nevertheless, this method must be completed by an actuator calibration stage to finally have a complete calibrated engine simulator. To accurately calibrate an engine simulator according to the increasing expectations leads to deal with more complex models under a wider range of operating conditions. Therefore, to facilitate complex process simulator 


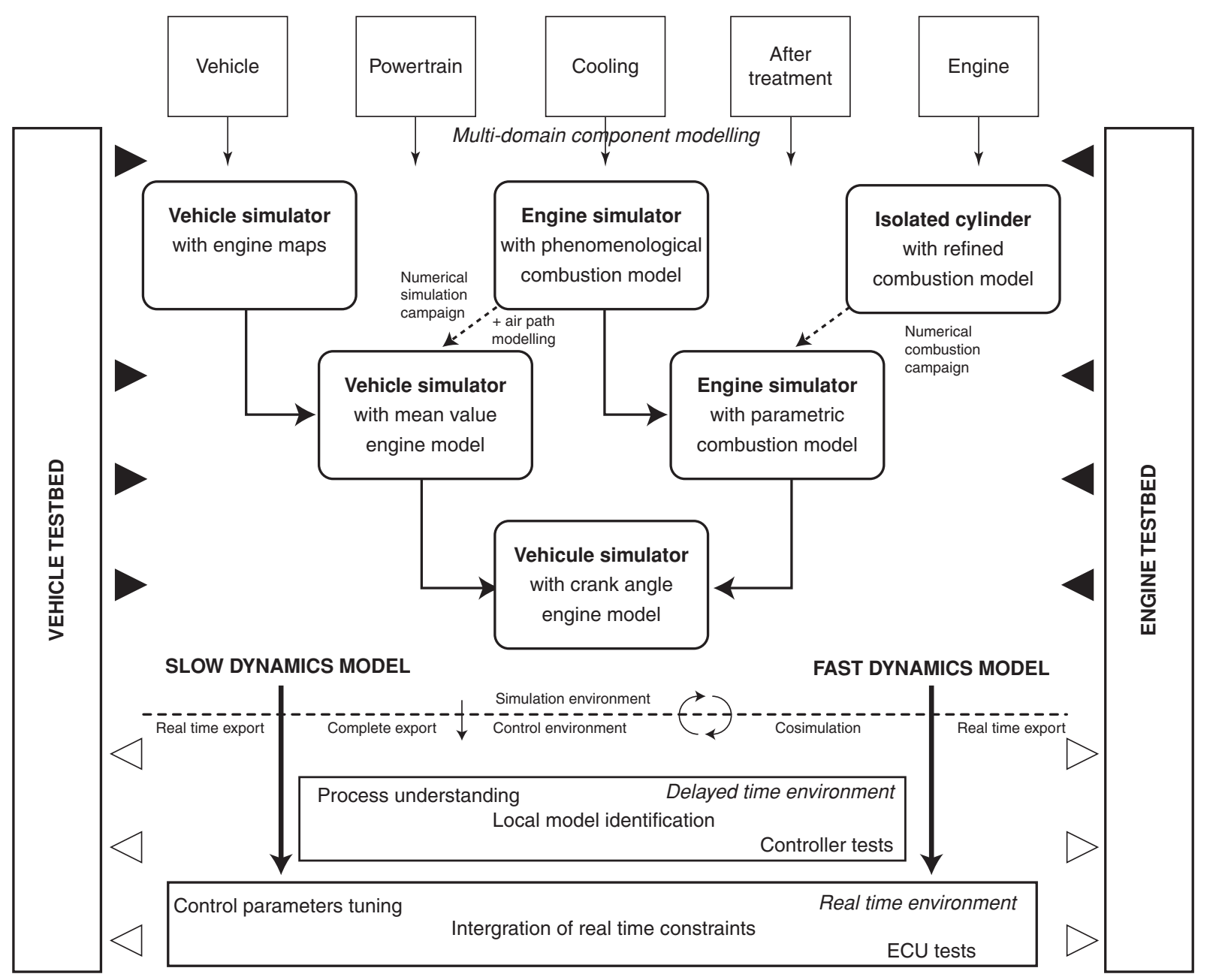

Figure 2

Simulator design and modelling levels.

calibration, a relevant approach is to settle some automatic calibration tools for part of the process. Such optimisation in the calibration methodology is one of the major challenges for simulator design to ensure an efficient use of the developed models. An illustration of such an automatic calibration tool is given in the next part with the crucial example of the combustion model calibration.

\subsubsection{Combustion Model Calibration}

To meet the control design objectives, the calibration automation of combustion models is becoming indispensable. Indeed, the calibration phase has to deal with the high number of combustion parameters (up to 18 for diesel models) but also the large set of representative operating conditions and accuracy requirements. That is why a specific tool has been developed to obtain the compromise that allows to get the best from the combustion model for the various requirements (IMEP, cylinder pressure deviation, noise, maximum pressure magnitude and angular location, etc.) and the wide operating condition range (from 10 to 80 set points). It is based on a strained non-linear optimisation approach taking into account a multi-parameter and a multi-criteria context.

The following figures present the results of an automatic calibration of the Chmela's Diesel combustion model and the Woschni's heat transfer model. Considering these two models, 14 parameters have to be calibrated. The process is achieved on 25 operating conditions at 1500, 2100 and $2500 \mathrm{rpm}$. The figures show comparisons between experimental and simulation results on instantaneous cylinder pressure of 4 operating conditions at $2100 \mathrm{rpm}$ (Fig. 3 to Fig. 6), but also the IMEP, the noise and the maximum cylinder pressure of the tested set points (Fig. 7 to Fig. 9). The results on the whole operating conditions are very correct and show the 


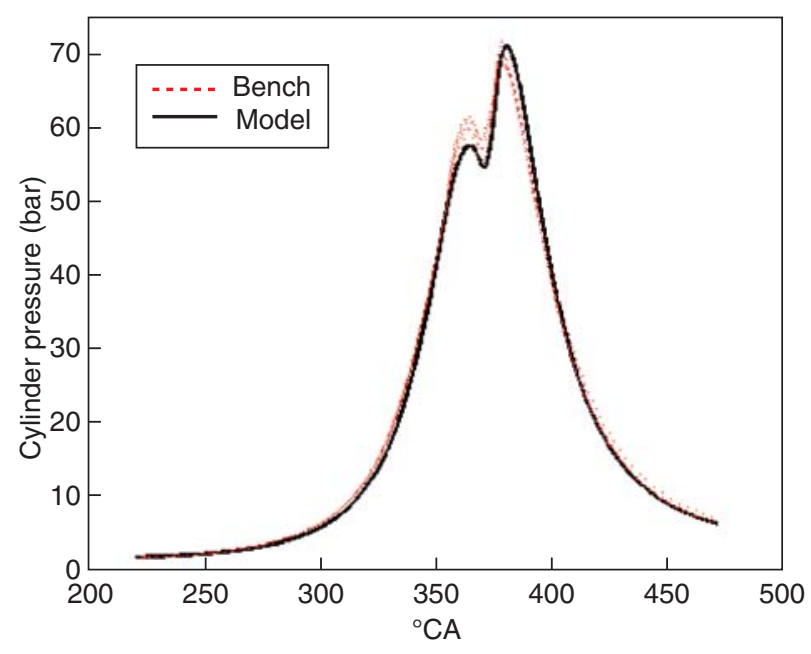

Figure 3

Model/bench result comparison for the cylinder pressure (2100 rpm, IMEP = 2 bar).

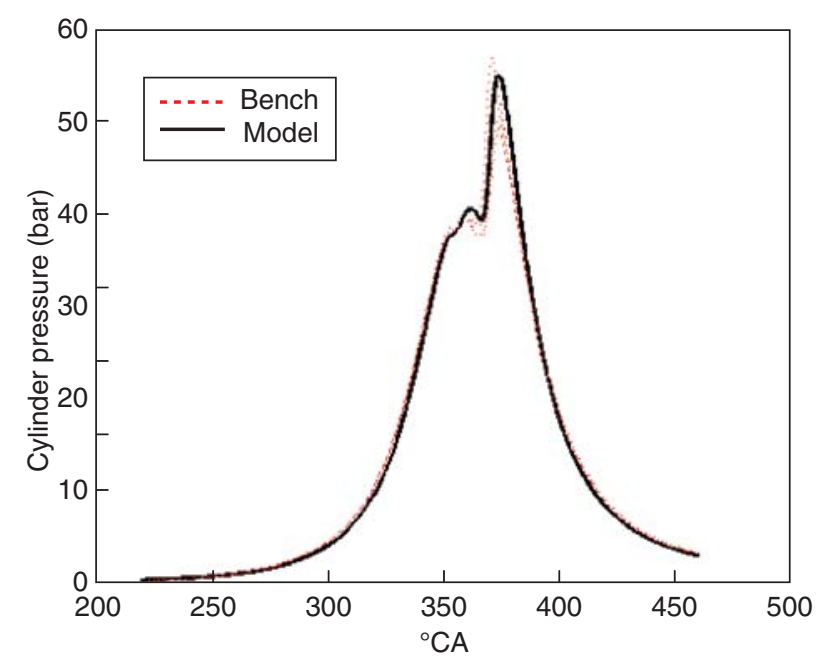

Figure 5

Model/bench result comparison for the cylinder pressure (2100 rpm, IMEP $=5$ bar).

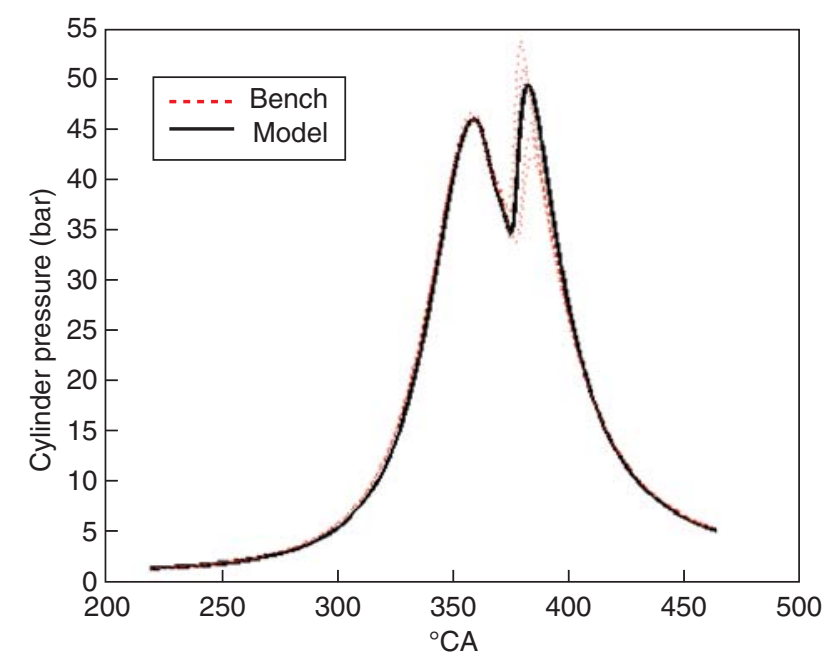

Figure 4

Model/bench result comparison for the cylinder pressure (2100 rpm, IMEP = 4 bar).

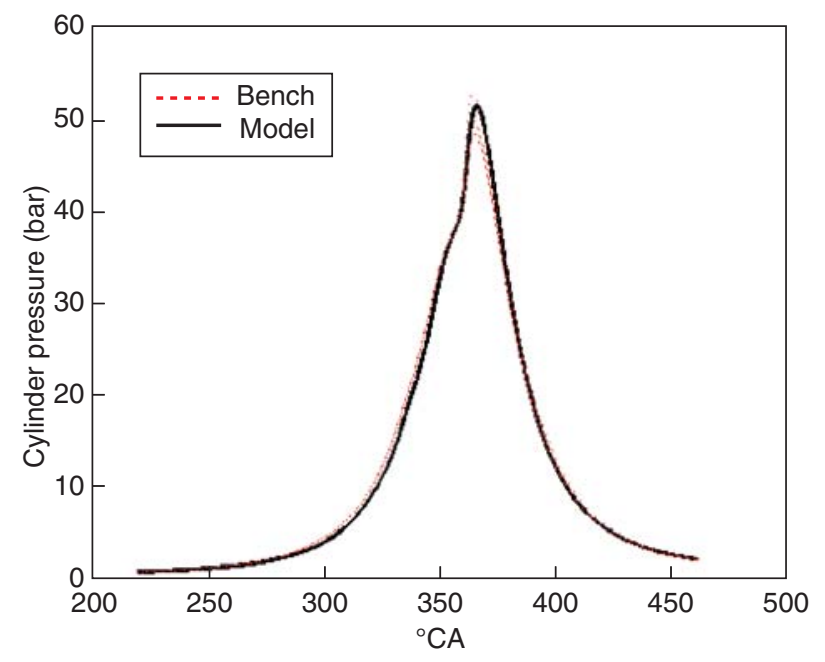

Figure 6

Model/bench result comparison for the cylinder pressure $(2100 \mathrm{rpm}, \mathrm{IMEP}=7.5 \mathrm{bar})$. relevance of the automation approach with all the constraints at stake.

\subsection{Simulator Validation}

To evaluate the simulator performances, an exhaustive validation is made under both steady state and transient conditions for simulator static and dynamic behaviour testing. As an example, the validation of the reference simulator of an HCCI Diesel engine using the combustion model from Section 2.3.2 is presented. More details about this simulator can be found in [17].

\subsubsection{Validation under Steady State Conditions}

The engine simulator is first evaluated on several steady state set points covering a large range of engine speeds and loads representative of the whole engine application field. For each operating condition, the simulator results are compared to test bed results in order to validate the simulator behaviour.

Figure 11 to Figure 14 show some result examples for the challenging case of HCCI engine simulator in the AMESim ${ }^{\circledR}$ environment (Fig. 10) tested on 86 set points from low load to full load for 5 engine speeds : 1500, 2000, 2750, 3000 and $4000 \mathrm{rpm}$. 


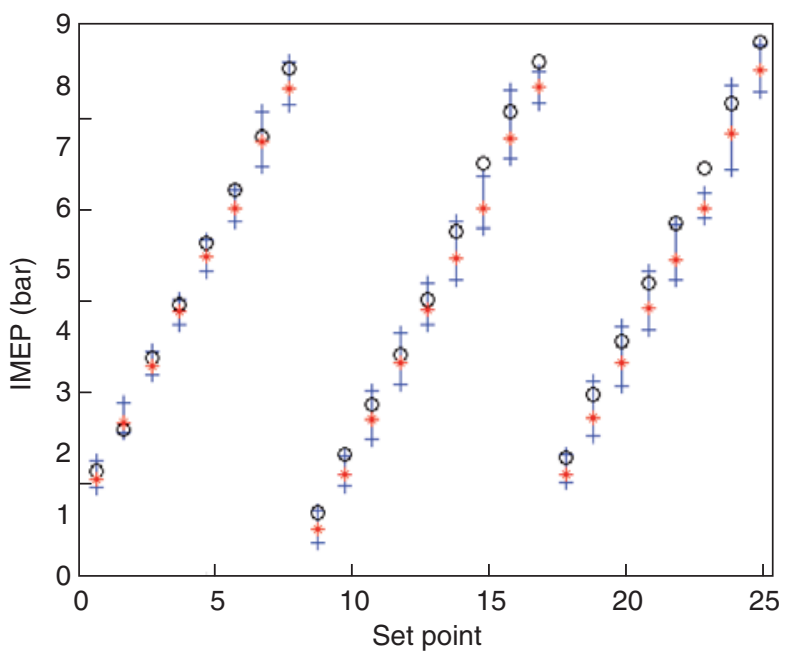

Figure 7

Comparison between model (circle) and bench (star) for the IMEP on the 25 operating set points - standard deviation range in solid line.

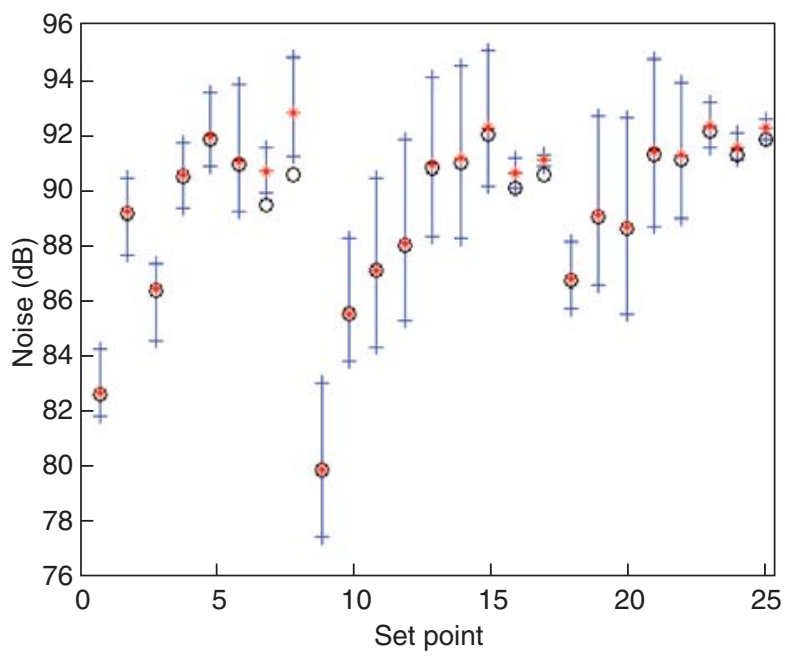

Figure 8

Comparison between model (circle) and bench (star) for the noise on the 25 operating set points - standard deviation range in solid line.

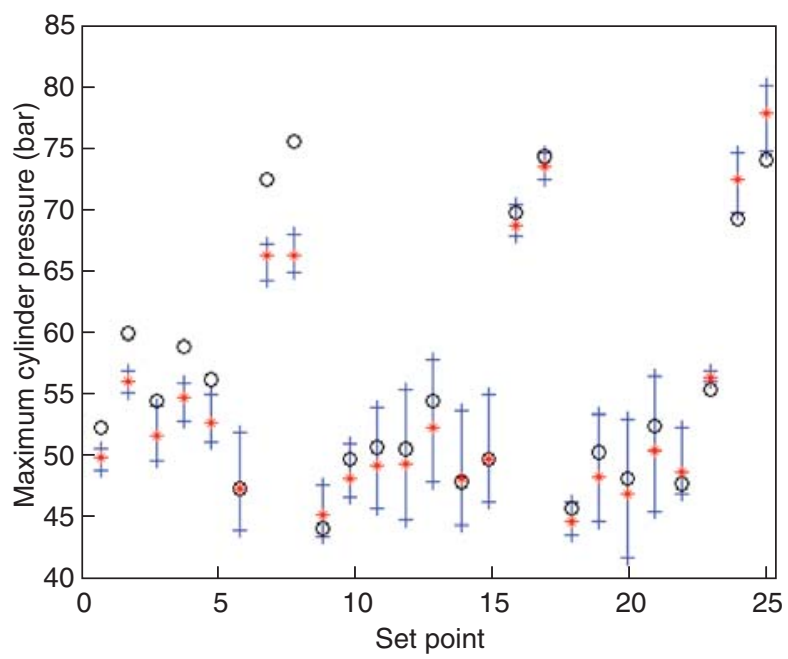

Figure 9

Comparison between model (circle) and bench (star) for the maximum cylinder pressure on the 25 operating set points standard deviation range in solid line.

This extensive validation insures the static behaviour of the simulator on several aspects: air path, turbocharger, combustion, thermal exchanges, etc. Nevertheless, to completely validate a simulator, a validation under transient conditions must also be carried out.

\subsubsection{Validation under Transient Conditions}

During the transient validation, the engine simulator results are also compared to test bed results to validate engine dynamic behaviour. Two methods are generally used to achieve these transient tests. The first one is an open loop test performed by applying to the engine simulator the actuator trajectories recorded at the bench during the same test. The simulator results are then compared to the bench engine results from the same test. It means that all the actuator targets are applied to the model with no engine control regulation. This open loop method is a really severe test for the model because any small deviation on the real engine test may be emphasised by the absence of engine control. The second method is a closed loop test. The engine simulator is coupled with the same engine control as the one used on the test bed in order to insure that the engine simulator and the real engine are controlled in the same way. A part or even all of the control regulations are applied to the simulator. It allows therefore to assess the engine simulator response without being influenced by actuator standard modelling limits such as hysteresis or dry friction at this stage.

Figure 15 to Figure 19 present the result examples of open loop transient tests for the same HCCI engine simulator on a $90 \mathrm{~s} \mathrm{tip} \mathrm{in/tip} \mathrm{out} \mathrm{transient} \mathrm{at} 1500 \mathrm{rpm}$ and a $200 \mathrm{~s}$ load trajectory at $1500 \mathrm{rpm}$. Figure 15 and Figure 16 present the engine simulator results during the tip in / tip out transient for the air mass flow rate and the exhaust equivalent Air/Fuel Ratio (AFR) which are the two main variables that have to be well reproduced by the model to deal with air path control issues such as the AFR or EGR observer design [17]. Figure 17 to Figure 19 present the engine simulator results during a load transient mixing conventional and HCCI combustion modes. The good agreement of the simulator dynamic behaviour obtained during these typical transients demonstrates the accuracy level of the engine simulator. 


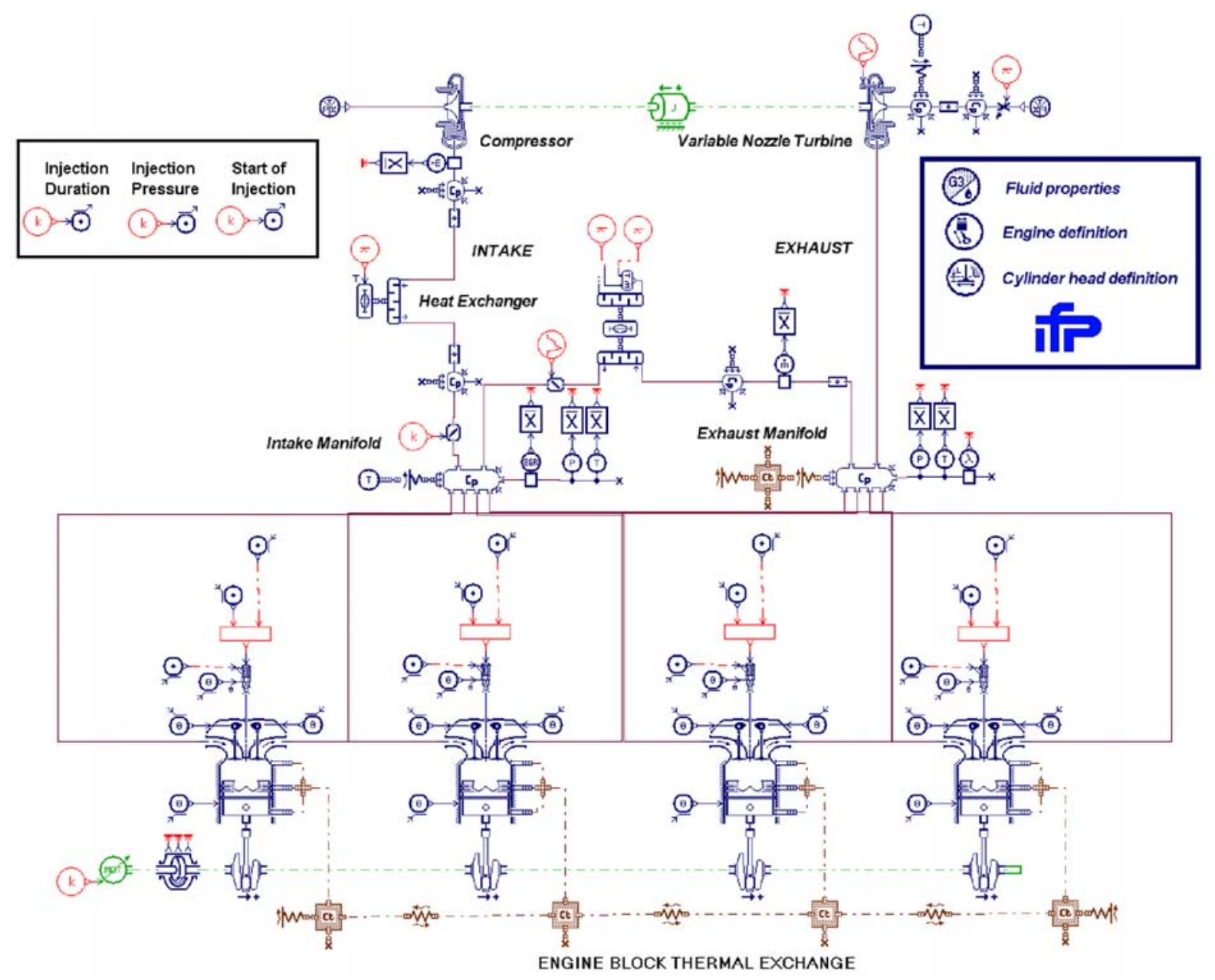

Figure 10

HCCI Diesel engine reference simulator with AMESim ${ }^{\circledR}$.

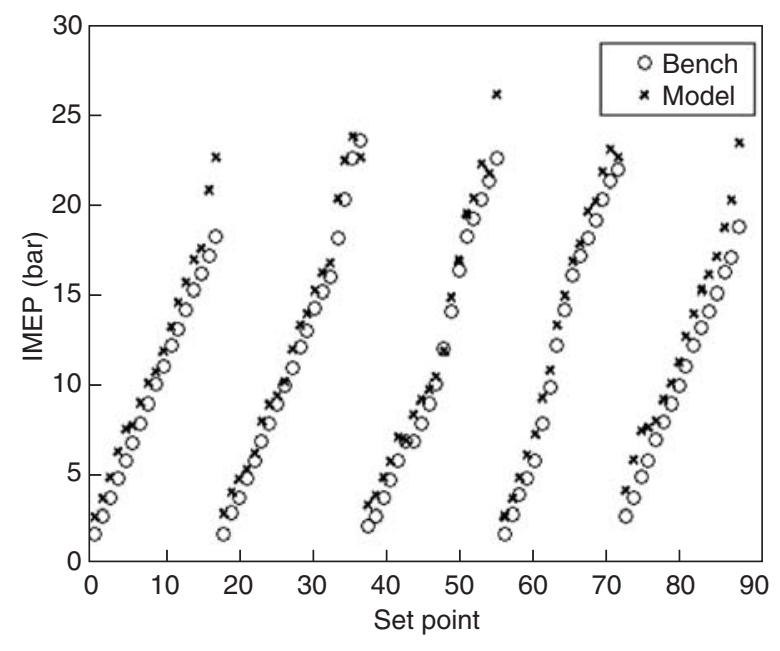

Figure 11

Model/bench result comparison for the IMEP.

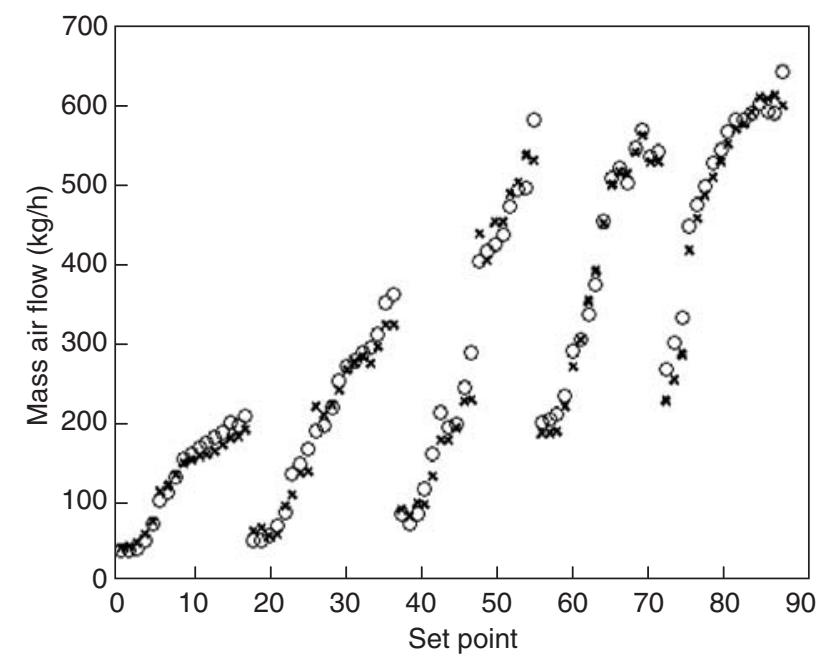

Figure 12

Model/bench result comparison for the Mass Air Flow. 


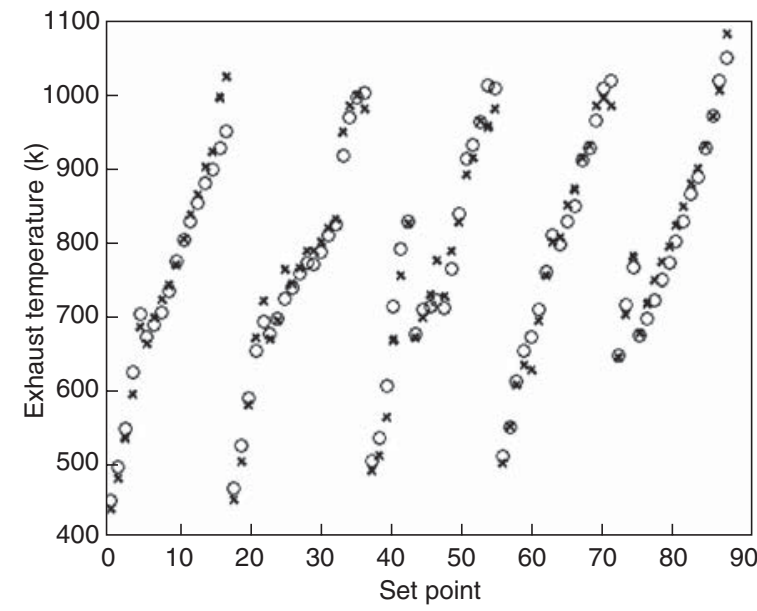

Figure 13

Model/bench result comparison for the exhaust temperature.

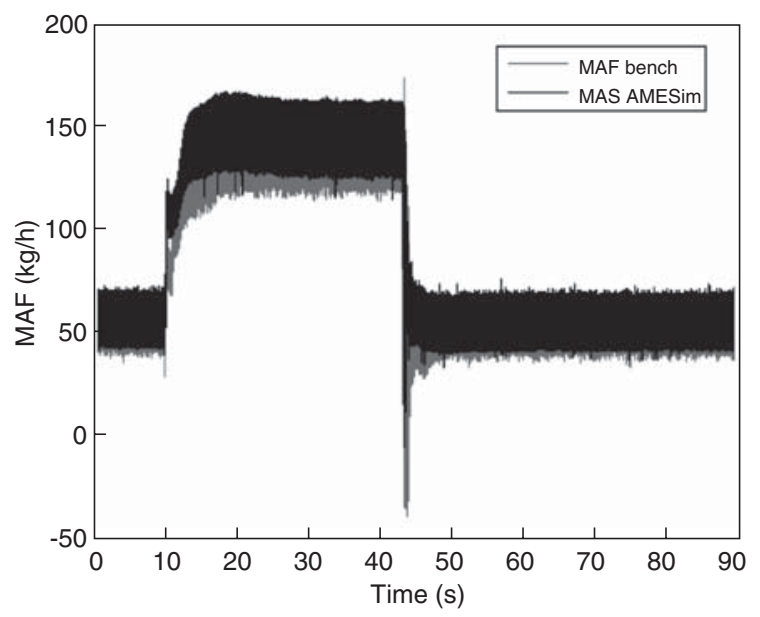

Figure 15

Model/bench mass air flow (MAF) comparison during tip in/tip out transient

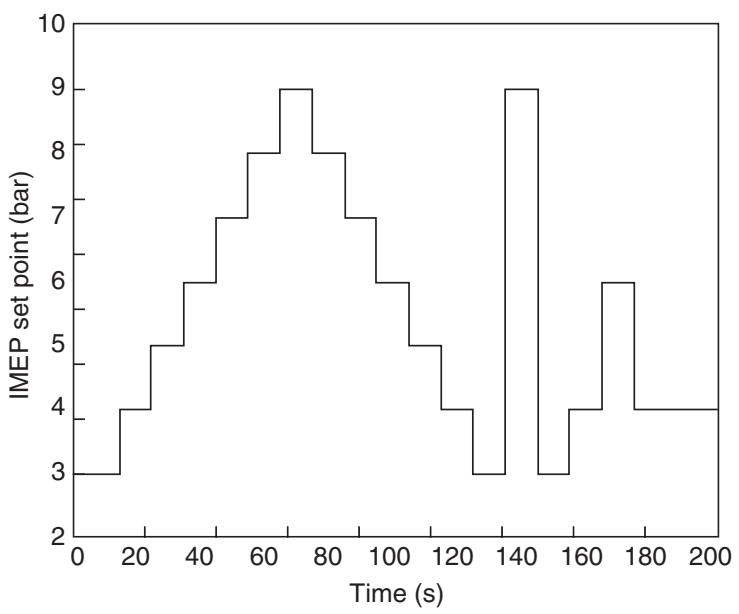

Figure 17

Target IMEP trajectory for load transient.

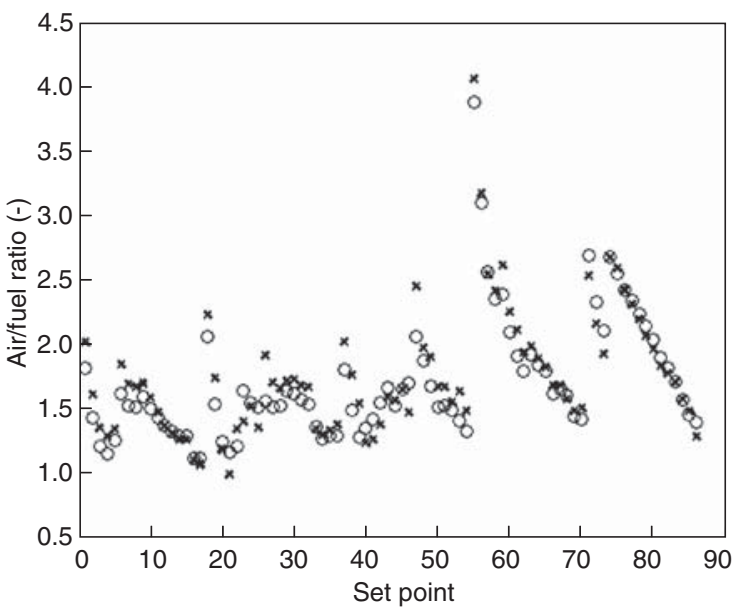

Figure 14

Model/bench result comparison for the equivalent Air/Fuel Ratio (AFR).

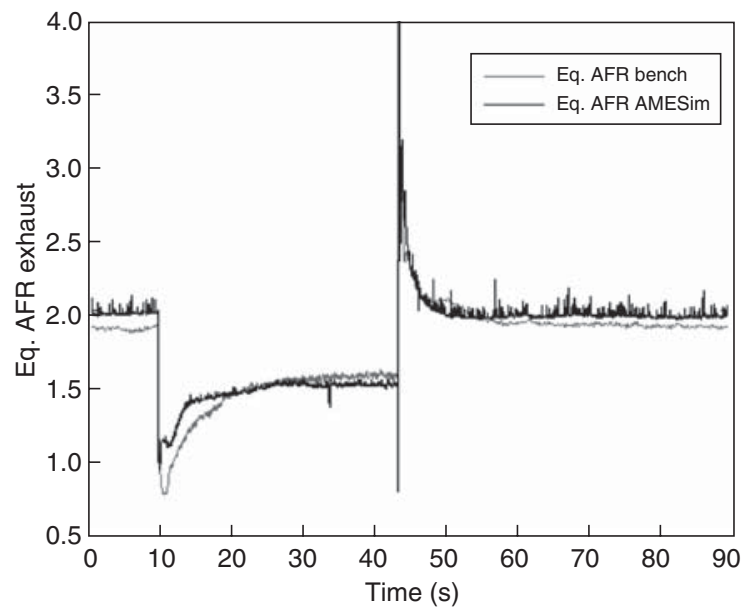

Figure 16

Model/bench exhaust equivalence air fuel ratio comparison during tip in/tip out transient.

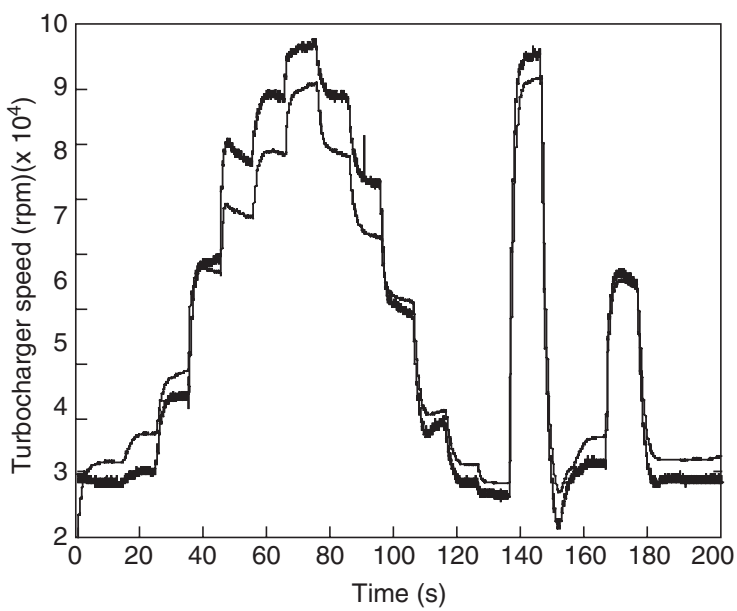

Figure 18

Model (solid line)/bench (dotted line) turbocharger speed comparison during load transient. 


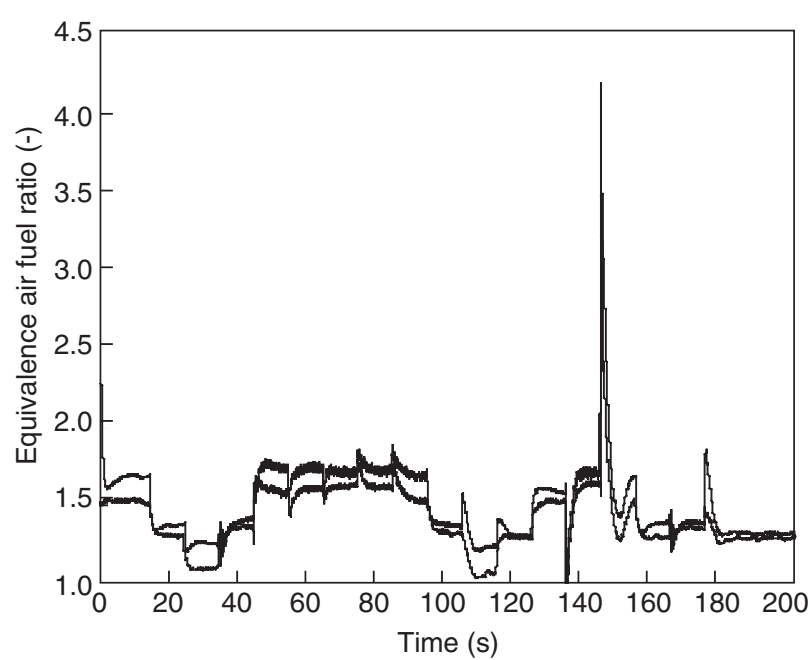

Figure 19

Model (solid line)/bench (dotted line) exhaust equivalence air fuel ratio comparison during load transient.

\section{CONTROL DESIGN METHODOLOGY USING SIMULATION}

This section illustrates the control development methodology based on engine simulation as a support tool. After a short recap of the simulation based control design philosophy (Sect. 3.1), three different IFP engine applications are proposed as illustrations. For each one, the main control issues will be presented with the corresponding control solutions and the simulation results. All the engine and vehicle simulators involved in these applications have been developed in the $\mathrm{AMESim}^{\circledR}$ environment, mainly with the IFP-ENGINE (engine simulation) and the IFP-DRIVE (vehicle simulation) libraries. The engine specifications for each case are summarized below:

\section{- $\mathrm{HCCl}$ Diesel Engine}

IFP has developed a combustion system able to reach near zero particulate and NOx emissions while maintaining expected performance of DI Diesel engines. The dual mode engine application called NADI (Narrow Angle Direct Injection) applies HCCI combustion at part load and switches to conventional Diesel combustion to reach full load requirements. The engine is a four cylinder lightduty direct injection Diesel engine working in both conventional combustion mode and HCCI combustion mode. The engine is a 2.2 litre standard production $(87 \mathrm{~mm}$ bore and $92 \mathrm{~mm}$ stroke). The combustion chamber has been designed following the $\mathrm{NADI}^{\mathrm{TM}}$ concept specifications with a specific piston bowl and a compression ratio of $14: 1[23]$.

\section{- Downsized Gasoline Spark Ignition Engine}

IFP starts from a standard four cylinders in-line engine, with direct injection technology (2 litre Renault F5R). IFP adapts this engine in order to reduce the displacement to 1.8 litres and to support an adapted turbocharged application (Mono-scroll type). To take advantages of all the potentialities of direct injection and turbocharging, the engine is equipped with two variable camshaft timing (VCT) systems for intake and exhaust valves.

\section{- Compressed Natural Gas Light Hybrid Engine}

In order to reach very low $\mathrm{CO}_{2}$ emissions IFP has developed a Compressed Natural Gas (CNG) hybrid Smart 600 cc Smart engine [24]. To improve torque at low speed, a mild-hybrid approach based on a $3 \mathrm{~kW}$ starter alternator supplies extra-power for peak load conditions. The starter alternator compensates the fuel penalty at low speed. The main objectives of this project are to confirm the high efficiency of compressed natural gas fuel used in urban conditions and to develop the associated control structure to manage the whole system (engine, starter alternator, clutch and gearbox).

\subsection{Simulation Based Control Design Philosophy}

During the model based control development cycle, the control requirements of engine simulation do evolve. In order to efficiently support the control design at each development step, different versions of the engine simulator take part in the control algorithm development and testing. The methodology presented in this paper is based on three engine simulators. The engine simulation takes part of the control law development at each step of the control design with the three following simulator versions:

\section{- The Reference Engine Simulator (Software-in-the-Loop Plafform)}

The goal of this simulator is to provide an engine model with a high representative capability of the real engine. It allows to investigate engine behaviour and to better understand the phenomena involved on the process to control. From the control point of view, this simulator is mostly used for steady state and short transient tests to support controller/observer design. This simulator is also very important for the engine simulation part because it is used as the reference accuracy level for the other simulator versions. It is therefore the most CPU expensive version (about 50 times the real time with a standard $3 \mathrm{GHz} \mathrm{PC}$ in the presented cases). The reference engine simulator is run in the AMESim/Simulink co-simulation environment. Three illustrative examples are presented in Section 3.2.

- The Fixed Step Simulator (Software-in-the-Loop Plafform) Once the basis of the control components is defined, the engine fixed step simulator is required to achieve further 


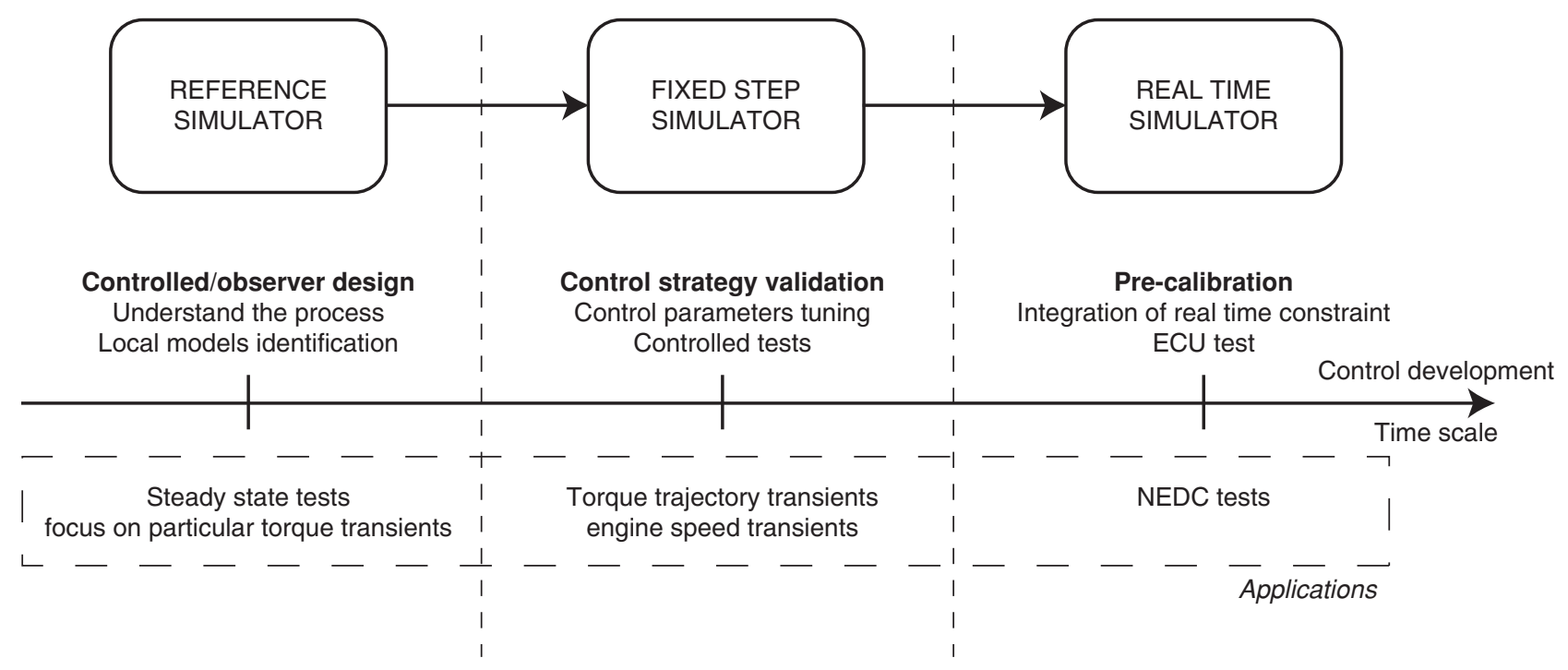

Figure 20

Schematic diagram of the engine simulation based control design methodology.

tests and to validate the control algorithm under a wider range of operating conditions before experimental validation. This simulator has to be able to be computed with a fixed time step solver and is supposed to run the engine tests with a reduced CPU time (about 10 times the real time with a standard $3 \mathrm{GHz} \mathrm{PC}$ in the presented cases) while preserving the relevant physical behaviour obtained with the engine reference simulator. Two illustrative examples are presented in Section 3.3.

\section{- The Real Time Simulator (Hardware-in-the-Loop}

\section{Platform)}

Finally, the real time simulator is used to perform hardware-in-the-loop (HiL) simulations with dedicated platforms such as XPC or dSPACE which allow testing the control in a configuration very close to the bench configuration. The hardware-in-the-loop platform is designed to test and validate the complete engine control implemented in a Simulink-based framework. The purpose of this HiL platform is not to reproduce all signal conditioning to be compliant with a standard ECU wires, but to be fully plugand-play with the engine control coming from the test bed or the vehicle to the engineer's desktop. The hardware component of the HiL platform is composed with a ATHLON 4.8 GHz PC with xPCtarget ${ }^{\circledR}$ real time operating system as the floating point power resource. Real-time exchanges with this engine control are ensured with a dual-port shared memory connected between the HiL platform and the engine control. This dual-port is synchronised with time events and engine events, TDC and $6^{\circ} \mathrm{CA}$ interruptions. Synchronised to these events, all inputs/outputs are exchanged from the engine simulator to the engine control. To avoid any modification of the engine control in Simulink, all xPC drivers for inputs/outputs used at the test bed are overloaded to exchange, in the same conditions, data through the dual-port memory board. The engine simulator is therefore required to run in real time which is achieved thanks to specific adaptations. The control law performances and robustness are then validated under much more realistic conditions than with the off line platform. For example, such a kind of simulations can help pre-calibration of controller parameters (especially when gain scheduling strategies are chosen). In addition, with the HiL platforms, the real hardware can be tested on simulated components. One illustrative example is presented on Section 3.4.

This simulation based control design philosophy is summarized in the scheme presented on Figure 20.

\subsection{Controller/Observer Design with the Reference Simulator}

This section presents three examples of simulation support with the reference simulator:

- BGR observer validation for the NADI ${ }^{\mathrm{TM}} \mathrm{HCCI}$ engine (Sect.3.2.1).

- Trapped gas mass observer for downsized SI engine (Sect. 3.2.2).

- Pull-away control strategy for the CNG light hybrid Smart vehicle (Sect. 3.2.3).

\subsubsection{BGR Observer Validation for the NADI ${ }^{T M}$ $\mathrm{HCCl}$ Engine}

The intake system of the G9T NADI ${ }^{\mathrm{TM}}$ engine includes two different parts (Fig. 21): the Exhaust Gas Recirculation 


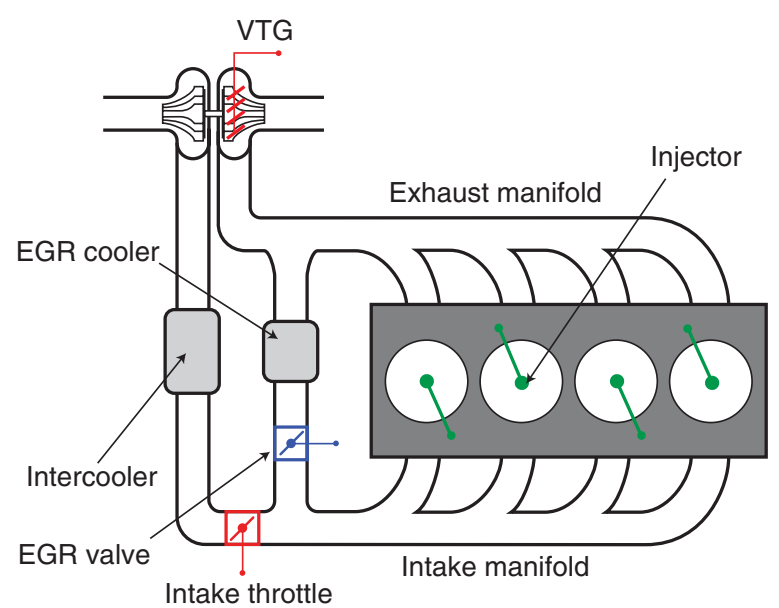

Figure 21

Four cylinder NADI ${ }^{\mathrm{TM}} \mathrm{HCCI}$ engine.
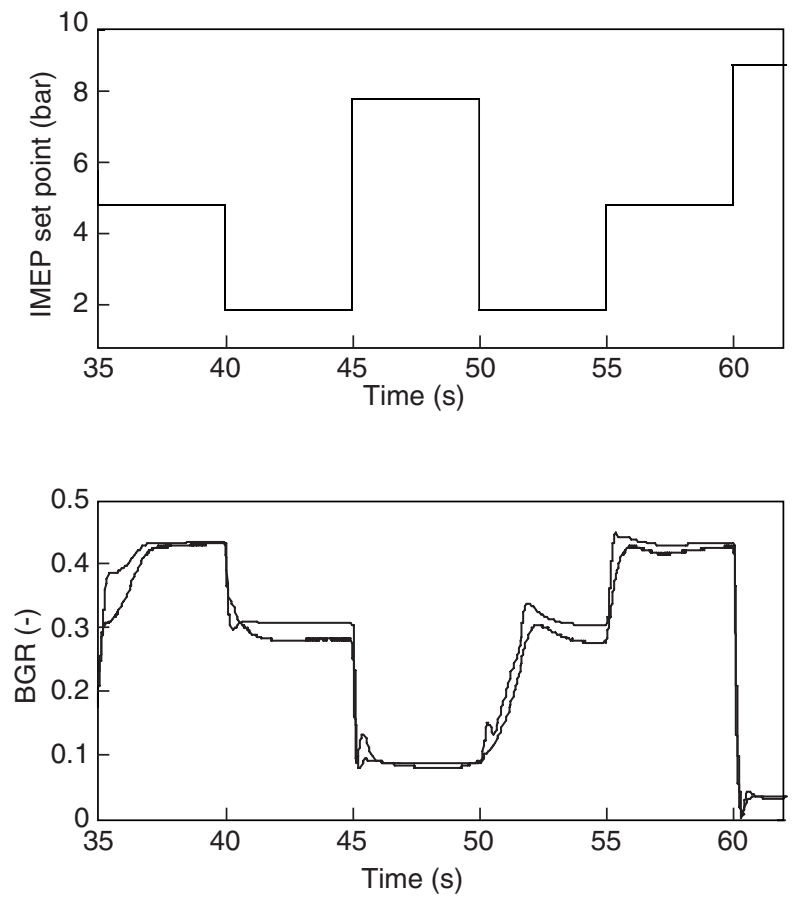

Figure 22

BGR observer validation: IMEP set point (top) and comparison between the estimated BGR (dotted line) and the BGR given by reference simulator (solid line).

(EGR) system and the turbocharger with one actuator each, the EGR valve and the variable geometry turbine (VGT). The composition and amount of gas entering the cylinder, and thus the combustion and the torque production, are controlled with these two actuators. Moreover, an intake throttle can also be added.
The exhaust gas recirculation is used to limit the flame temperature and reduce the NOx emissions at low engine load. In these conditions, the engine operates with very high levels of Burnt Gas Ratio (BGR). However, these levels cannot be maintained as the engine load increases, and the engine runs under conventional conditions at higher loads with low BGR level (part load) or no BGR (high load). The turbocharger works mainly at high engine loads, where boost pressure is needed to reach the expected IMEP.

From the air path control point of view, two major issues have to be considered: the observation and the control of intake manifold variables. Usually, the feedback variables for combustion control are the intake manifold pressure and the BGR. The development of the control strategy is described in [25].

Since the BGR is one of the key variables in HCCI combustion, it must be accurately controlled. However, the direct measurement of this variable cannot be achieved on mass production engine. Thus, without gas composition sensor, BGR estimation must be computed from other measurements. The BGR observer design is based on a simplified "filling and emptying" model of the intake manifold issued from the thermodynamic first law [25]. The BGR observer validation using the reference simulator is displayed on Figure 22.

After the BGR observer validation, the engine simulator was used to evaluate the impact of the intake throttle on BGR control. In the first step, the air and EGR mass flows was separated. The VGT controls the air flow and the EGR vane the burnt gas flow into the intake manifold. The baseline control strategy relies on these two actuators. However, the air loop and the fuel loop are strongly linked and an intake throttle control was added in order to enhance the BGR control. The first evaluation of benefits carried out by using three actuators instead of two is performed on the engine model. The simulated results of the two control strategies performed at $1500 \mathrm{rpm}$ during a torque trajectory are presented on Figure 23. The intake throttle closes when the BGR level is difficult to reach. That is the case during the 8 bar to 2 bar IMEP transient: the EGR vane is fully open but the BGR level cannot be reached since there is a strong deviation between injected fuel mass from 8 to 2 bar of IMEP (at time 50 seconds on Fig. 23). Thus, the exhaust equivalence ratio significantly drops. This perturbation cannot be rejected by the air path controller when the intake throttle is not used. During transient operating conditions, the intake throttle gives a faster and more accurate BGR tracking. Here, the engine simulations give relevant information about the feasibility to apply this method and about the engine behaviour when another actuator is added in the air path control structure.

\subsubsection{Trapped Gas Mass Observer for Downsized SI Engine}

The air intake system of a turbocharged SI Engine is represented in Figure 24. The compressor (pressure Pint) produces 

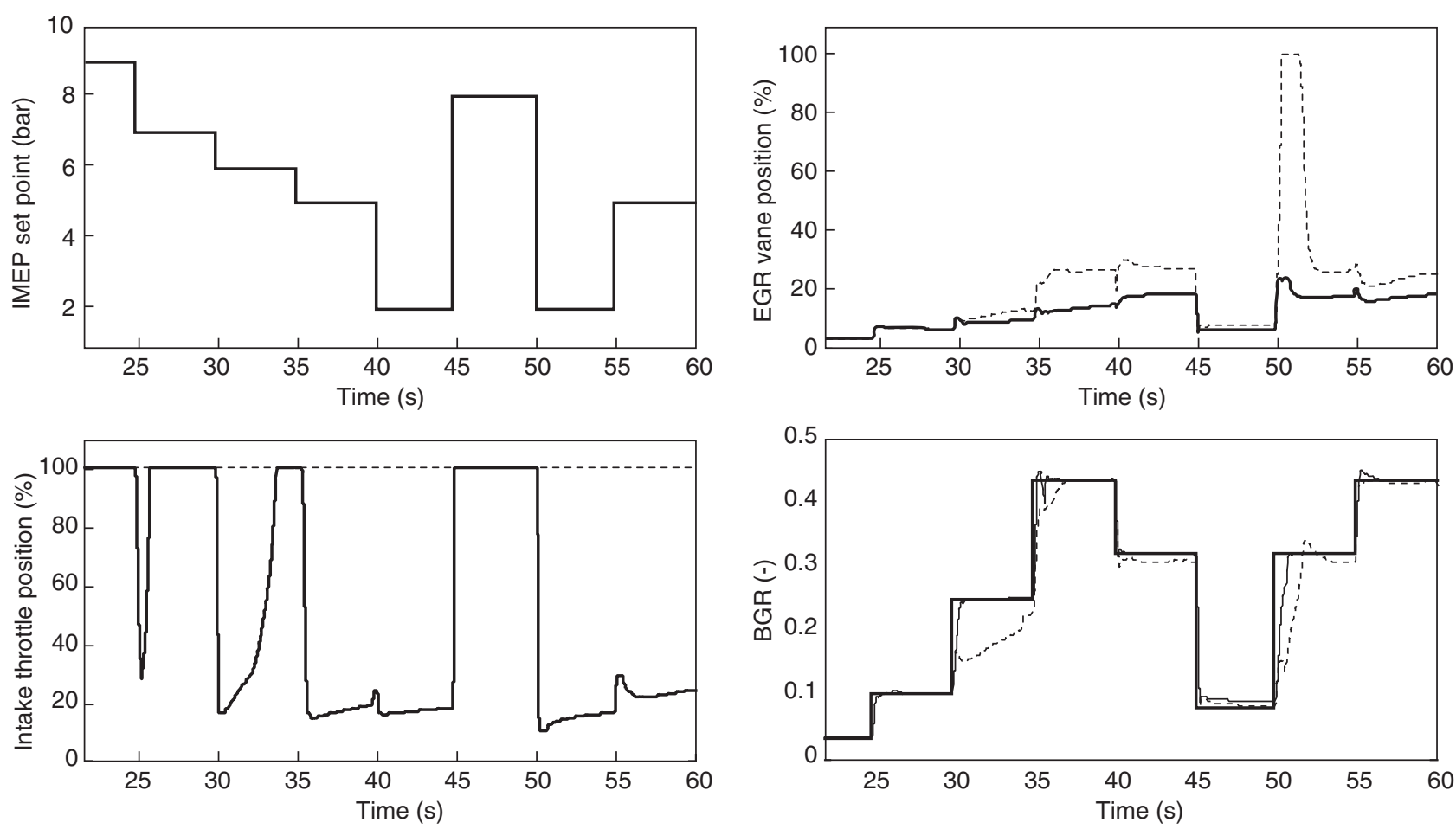

Figure 23

IMEP transient test at fixed engine speed (1500 rpm) with comparison of two different control strategies: (1) without intake throttle (dotted lines) and (2) with intake throttle control to enhance the BGR control (solid lines).

a flow going through the throttle into the intake manifold (pressure $P_{\text {man }}$ and temperature $T_{\text {man }}$ ). The torque is directly linked to the air mass trapped in the cylinder (from $D_{c y l}$ ) for a given engine speed. An efficient observation and control of the air mass trapped in the cylinder is required to obtain the desired torque.

The effects of Variable Camshaft Timing (VCT) can be summarized as follows. On one hand by acting on the cam timing, when exhaust pressure is greater than manifold pressure, a part of burned gases are retained in the cylinder during the subsequent intake stroke. This dilution of the mixture in the cylinder reduces the combustion temperature and limits the NOx formation. Therefore, it is important to control an optimal value of burned gases in the cylinder.

On the other hand, if valves are opened together and the intake manifold pressure greater than exhaust pressure, air scavenging appears. It decreased the turbocharger and engine torque response. In transient, it is very important to control this air scavenging. A standard approach for the estimation of the air mass trapped in the cylinder is based on volumetric efficiency [28]. Without VCT, volumetric efficiency depends only of engine speed and intake manifold pressure and can be represented by a 2D look-up table. With VCT, engine mapping on test bed provides optimal positions for VCTs in warm conditions for each (engine speed, IMEP) optimal operating point.
In order to control an optimal trajectory of air mass in transient and different valve timing VCT positions have to be taken into account. To be exhaustive, even with a design of experiment methodology, it would need a large amount of tests in order to cover a wide range of operating conditions. A recirculated mass model of burned gases or air scavenging according to valve overlap and intake and exhaust pressures is also needed because it can not be directly measured.

A preferred methodology is thus to build models using the reference engine simulator. As this physical model is too complex to be directly embedded, black-box solution as neural networks become an attractive technique for this purpose. An exhaustive learning process can then be achieved using an extensive numerical campaign issued from the reference simulator as the learning base (about 6800 points: manifold pressure from 0.3 to 2.4 bars, engine speed from 750 to $5500 \mathrm{rpm}$, and intake and exhaust valve timing overlap on a 40 crankshaft angle range). This learning base would have been more difficult to perform at the test bed and would have increased drastically the ANN model cost. These ANN models are then validated on a different base (about 80 points) covering the engine mapping (engine speed, IMEP). Figure 25 compares the neural model and the simulator results for trapped air mass and recirculated gas mass on these set points. Final experimental bench results are presented in [27] and demonstrate that the engine simulator accuracy is adapted for such a use. 


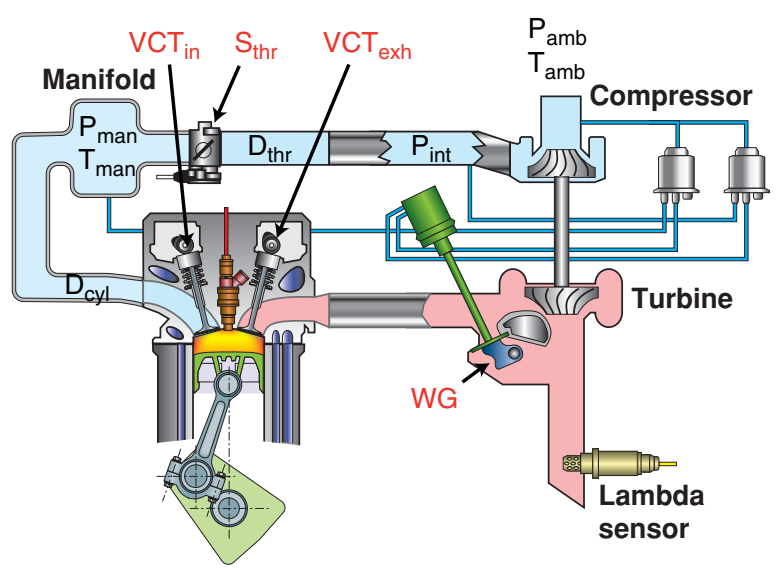

Figure 24

Air intake of a turbocharged SI engine with VCT.

\subsubsection{Pull-Away Control Strategy for the CNG Light Hybrid Smart Vehicle}

An automated manual transmission (AMT) includes a gearbox and a dry clutch, where both gearbox and clutch positions can be controlled by specific actuators. The AMT control for the Smart vehicle is a challenging control issue, since the system dynamics are fast and highly nonlinear. Clutch position control is a crucial task for starting off the vehicle. This section focuses on the vehicle pull-away problem. The main issues for this task are:

- to avoid engine stalling (no kill condition),

- to avoid engine speed overshoot,

- to minimize oscillation to preserve the powertrain and to improve the drivability (no lurch condition).
These objectives can be taken into account by using multivariable control techniques. The problem can be simplified to a multiple SISO feedback by determining feasible trajectories. The main input is the torque set point requested by the driver to move the vehicle. In order to achieve this torque demand two set points are computed:

- the engine torque,

- the clutch position.

The engine torque control structure is in charge to track the torque trajectory set point by applying the adequate control actions for the engine actuators (throttle, injector, etc.). Another feedback has to control the clutch position. The available measurements are the clutch position, the engine speed, the vehicle speed and the primary shaft speed. The engine torque and the clutch torque are not measured but their values can be estimated using observers. Further details concerning the control algorithm can be found in [29].

Tests and validation of the integrated powertrain control system are carried out in a co-simulation framework with a Smart vehicle simulator (Fig. 26).

The results of a pull-away control are displayed in Figure 27. The engine speed does not show any strong fluctuations. This proves the relevance of the chosen strategy. From that point, the control algorithm can be tested directly on the demonstrator vehicle.

\subsection{Control Strategy Validation with the Fixed Step Simulator}

In this section, the fixed step simulator use is highlighted through two different engine applications:

- Smoke limitation strategy for HCCI Diesel engine (Sect.3.3.1).

- Closed-loop trapped air mass observer for downsized SI engine (Sect. 3.3.2).
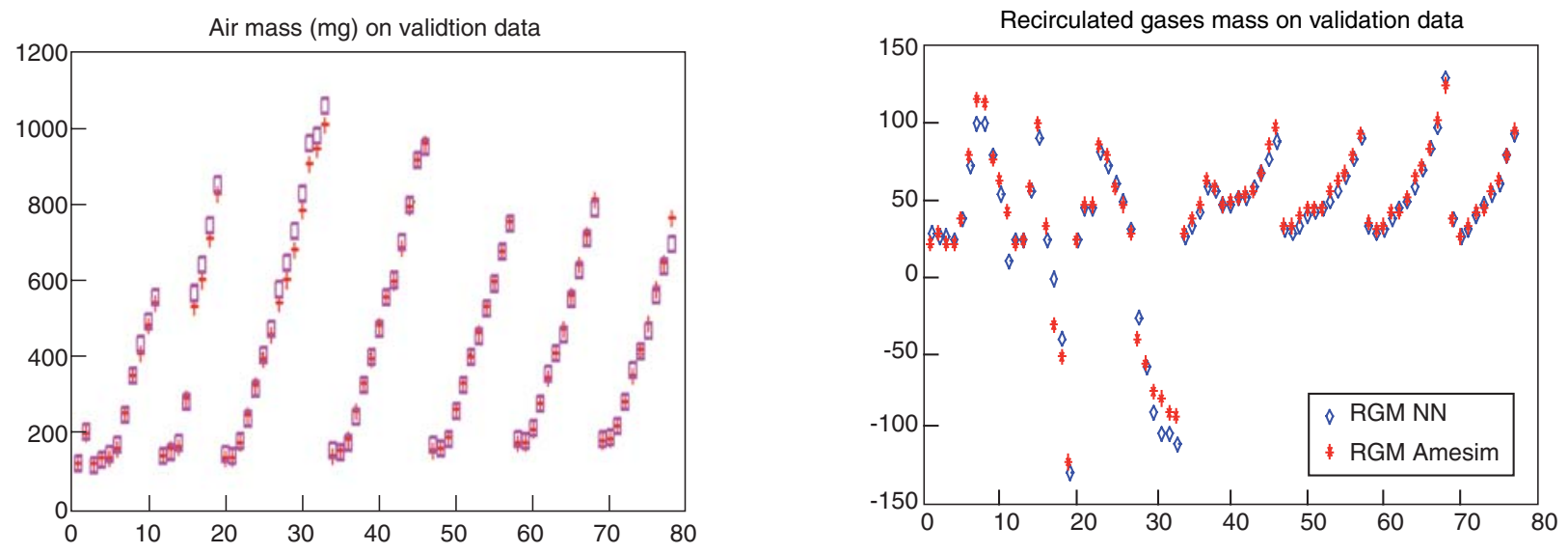

Figure 25

In-cylinder trapped air and recirculated gas mass neural model and simulator results comparison on validation base. 


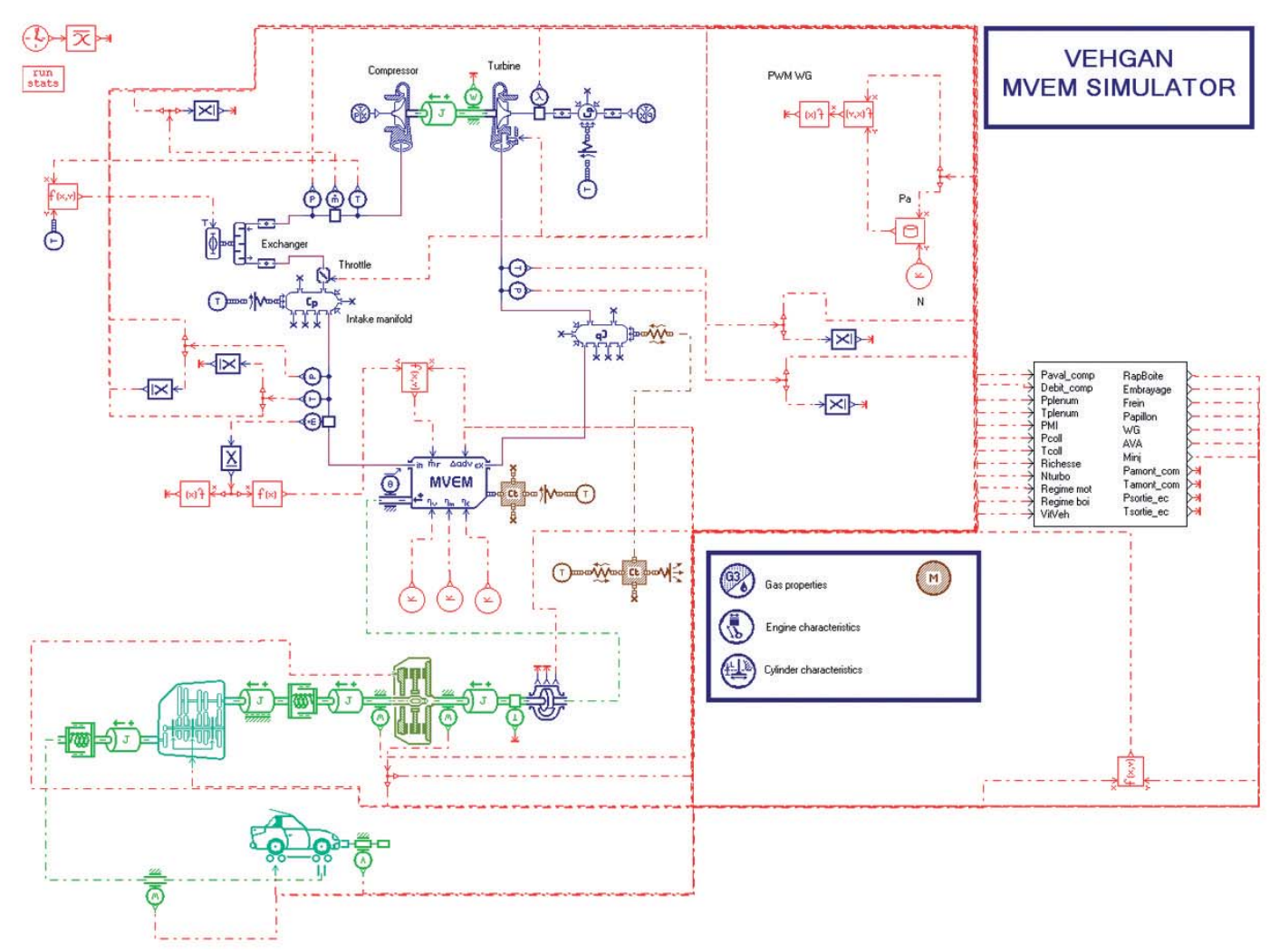

Figure 26

AMESim ${ }^{\circledR}$ Smart vehicle simulator.

\subsubsection{The Smoke Limitation Strategy for HCCI Diesel Engine}

The challenge with HCCI engine is to maintain the adequate thermodynamic conditions for each cylinder by using modern actuators fitted to the engine. This involves applying robust control techniques. The key point to ensure stable HCCI operating conditions is to optimize the injection settings, BGR level and boost pressure. Combustion control is a key point for $\mathrm{HCCI}$ engine expansion to mass production vehicles.

In this section, the advantage of using a model in the development of fuel control strategy is illustrated. This example briefly described a fuel path control strategy to limit the smoke emission during large IMEP transients (tip in). The smoke emissions are mainly caused by a lack of air during transient operating conditions. The fuel loop has a very fast dynamics and the air loop related variables (boost pressure, air flow, BGR level) are slower. This effect is increased when the fuel is fed to the cylinder without taking into account the air dynamics. Without any specific strategy, the engine emissions raise and misfires may occur (in cylinder mixture is saturated).

The method is based on the estimated air mass flowing into the cylinders. The air flow entering the cylinder is estimated using a state observer described in [25]. A maximum equivalence ratio is fixed, the maximum allowable fuel flow can be easily deduced from equivalence ratio measurement.

Since we know the maximum fuel mass, we can compute the corrected IMEP set point. The injection look up table gives the fuel mass as a function of the IMEP set point and the engine speed. The corrected IMEP set point is computed by inversion of the injection mapping.

Here, the fixed-step simulator was use to tune the smoke limiter strategy during the tip in transient. The tuned parameter is the in-cylinder equivalence ratio limit. The output variable is the exhaust equivalence ratio which is related to the smoke emissions.

The best equivalence ratio limit must ensure a good trade off between the exhaust equivalence ratio peak reduction and the engine torque response. Figure 28 displays the IMEP set points computed with several values of equivalence ratio limit performed with the fixed step simulator. The smoke limitation strategy acts as a filter on the raw IMEP set point. As a consequence, the fuel mass will be injected with a delay depending on the equivalence ratio limit. Here we choose to limit fuel mass in order to operate near to stoichiometry. This choice leads to an acceptable trade off. For a more stringent limitation, the equivalence ratio peak occurring during the transient can be avoided but the torque response is too slow and may affect agreement. 

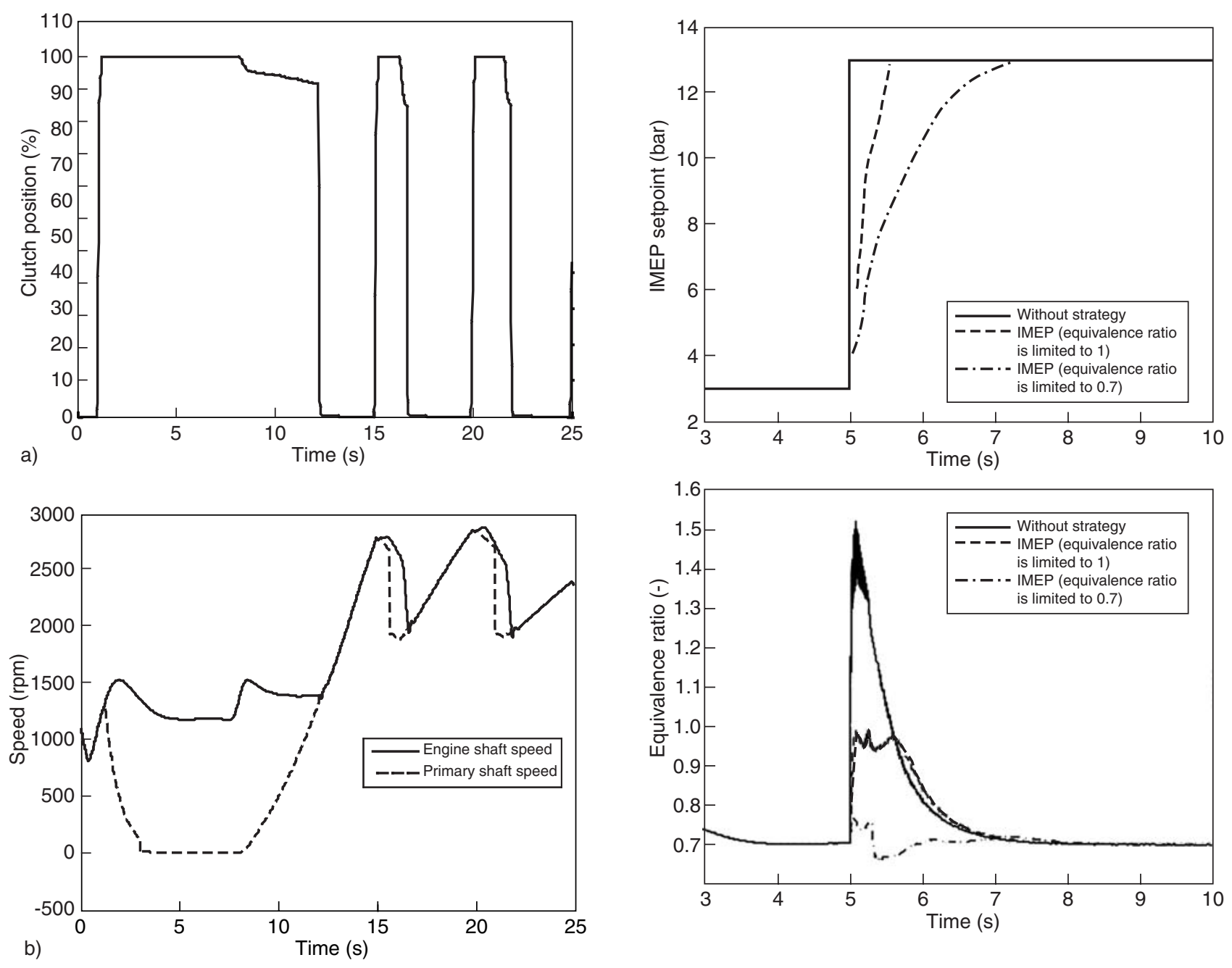

Figure 28

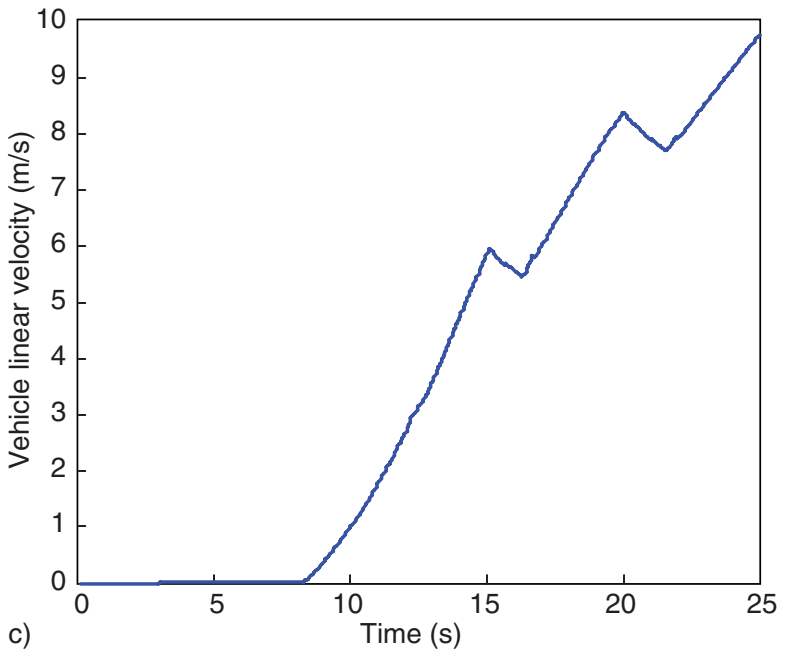

Comparisons of IMEP set points (top) and simulated exhaust equivalence ratio (bottom) with and without smoke limitation strategy. Simulations are performed with the fixed step simulator.

\subsubsection{Closed-Loop Trapped Air Mass Observer for Downsized SI Engine}

Validation of neural models presented in Section 3.2.2, on test bed shows that air mass neural feed forward model is not so accurate mostly for low load.

In order to dynamically reduce those static error, a Kalman filter based on intake manifold pressure equation and using air flow rate measurement has been design in fixedstep simulation [27]. Considering a slow air flow error variation and constant intake temperature, manifold pressure equation is transformed in a discrete state representation for Kalman filter. Its measurement and state noise covariance

matrix have been identified looped on fixed-step simulator.

Clutch position in \% (a), primary shaft speed and engine shaft speed in rpm (b), and vehicle linear velocity in $\mathrm{m} / \mathrm{s}$ (c). This test corresponds to the pull-away phase followed with two gear shifts. 


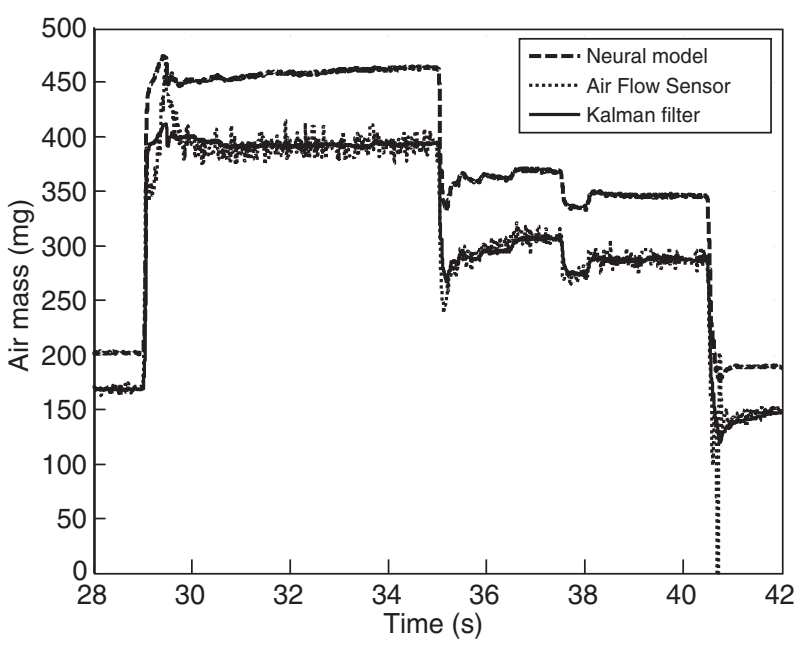

Figure 29

Kalman filter results on fixed-step simulator.

Figure 29 shows results of Kalman filter closed-loop in simulation. During this test, an offset was applied on neural model in order to voluntary increase estimation error and see closed-loop efficiency. It clearly shows its interest. Using air flow rate measurement eliminates model static error without adding measurement noise and pumping during transients (i.e. at $29 \mathrm{~s}$ and at $40.5 \mathrm{~s}$ ) on air mass trapped observation.

\subsection{Pre-Calibration with the Real Time Simulator}

The real time simulator is a very flexible tool to simulate and to pre-calibrate the engine control strategies over longer transient tests or wide range of operating conditions. This section presents the illustrative example of the air path and fuel path controller evaluation over the ECE test for the $\mathrm{HCCI}$ $\mathrm{NADI}^{\mathrm{TM}}$ engine. Here, we choose to evaluate the potential of the smoke limitation strategy during the urban driving ECE cycle with the corresponding torque and engine speed profiles displayed on Figure 31. This transient test lasts $200 \mathrm{~s}$.

The validity of the air loop control is evaluated by observing the EGR and air mass flows in first. The fuel loop controller (including the smoke limiter system) is validated by observing the exhaust equivalence ratio which is highly correlated with the opacity. The simulated results are shown on Figure 31 and some conclusions can be drawn:

- The EGR control is fast and accurate, the actual controller does not need any other improvement to track the EGR flow set point (the set point and the estimated values are superimposed).

- The air flow control is slower and there is a static error during large IMEP transients. This point requires some improvements.

- The exhaust equivalence ratio agrees with expected results since its maximum value remains under the settled limit (equivalence ratio is lower than one).

As a conclusion, the global engine behaviour is correct and the developed engine controllers can now be tested on the engine bench with the controller pre-calibration which will be refined at the bench.

\section{CONCLUSION}

A methodological point of view about engine modelling and simulation development has been presented including a continuous modelling approach, simulator design aspects and
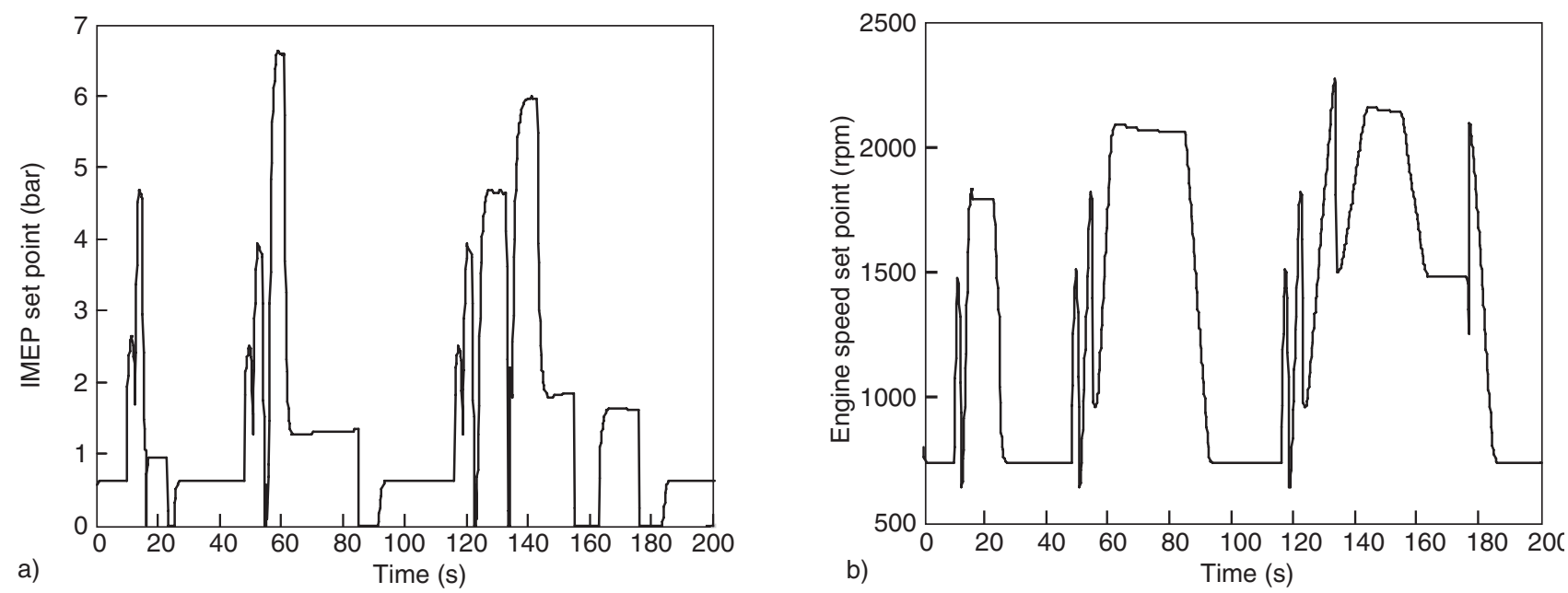

Figure 30

IMEP and engine speed set points for the ECE driving cycle. 

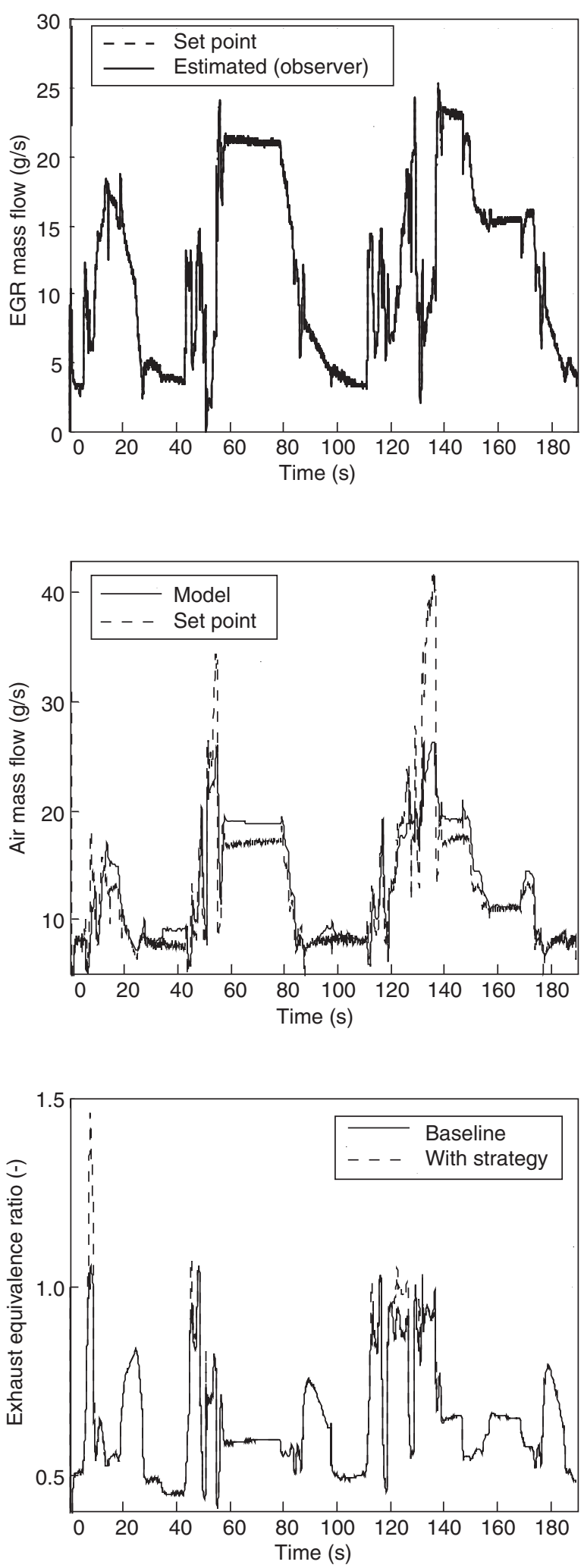

Figure 31

HiL simulation results on ECE transient test: EGR mass flow (top), air mass flow (middle) and exhaust equivalence ratio (bottom). software environment requirements. Then, the engine simulation based control design methodology has been described. The IFP approach relies on various simulator versions adapted to each control design stage. The three main versions are the reference, the fixed step and the real time engine simulators. The last part of the paper illustrates this simulation based philosophy with several examples issued from IFP engine development projects. Thanks to this complete and detailed presentation, the authors demonstrate how simulation is a very efficient tool for advanced engine control design support as it is already experimented at IFP.

\section{ACKNOWLEDGEMENTS}

The authors want to acknowledge Paolino Tona, Philippe Moulin and Pierre Gautier for their technical contributions.

\section{REFERENCES}

1 A. Albrecht, V. Thomas and G. Corde, Simulation système moteur : un élément incontournable de la chaîne de conception du contrôle moteur, Ingénieurs de l'Automobile Magazine, SIA edition, $\mathrm{n}^{\circ} 775$ bis, April, 2005.

2 O. Grondin, R. Stobart, H. Chafouk and J. Maquet, Modelling the compression ignition engine for control : review and future trends, SAE paper 2004-01-0423, 2004.

3 A. Albrecht, Ph. Moulin, O. Grondin and G. Corde, Control design for HCCI combustion engine based on virtual engine simulator: from control development to real-time calibration, Proc. of THIESEL Conference, Valence, Spain, 2006.

4 O. Colin, A. Pires da Cruz and S. Jay, Detailed chemistry based auto-ignition model including low temperature phenomena applied to 3D engine calculations, 30th Symp. (Int.) on Combustion, The Combustion Institute, Pittsburgh, pp. 2649-2656, 2005.

5 H. Barths, C. Antoni and N. Peters, Three-dimensional simulation of pollutant formation in a DI Diesel engine using multiple interactive flamelets, SAE paper 982459, 1998.

6 S.B. Pope, Pdf methods for turbulent reactive flows, in Progress in Energy and Combustion Science 11, Sybley School of Mechanical and Aerospace Engineering, 1985.

7 O. Gicquel, N. Darahiba and D. Thevenin, Laminar premixed hydrogen/air counterflow flame simulations using flame prolongation of ildm with differential diffusion, Symposium of Combustion 28, pp. 1901-1908, 2000.

8 G. Mauviot, A. Albrecht and T.J. Poinsot, A new 0D approach for Diesel combustion modeling coupling probability density function with complex chemistry, SAE technical paper, to be published in the proceedings of the $S A E$ Powertrain \& Fluid Systems Conference \& Exhibition, Toronto, Canada, October 16-19, 2006.

9 H. Hiroyasu and T. Kadota (1983) Development and use of a spray combustion modeling to predict Diesel engine efficiency and pollutant emissions. Part 1 . Combustion modeling. B. JSME, 26, 214.

10 D.T. Hountalas, D.A. Kouremenos, G.C. Mavropoulos, K.B. Binder and V. Schwarz, Multi-zone combustion modelling as a tool for DI diesel engine development Application for the effect of injection pressure, SAE paper 2004-01-0115, 2004. 
11 I. Arsie, F. Di Genova, A. Mogavero, C. Pianese and G. Rizzo, Multi-zone predictive modelling of common-rail, multi-injection Diesel engines, SAE paper 2006-01-1384, 2006.

12 J. Arregle, J.J. Lopez, J. Martin and E. Mocholi, Development of a mixing and combustion zero-dimensional model for Diesel engines, SAE paper 2006-01-1382, 2006.

13 P. Emery, F. Maroteaux and M. Sorine (2003) Modeling of combustion in gasoline direct injection engines for the optimization of engine management system through reduction of three-dimensional models to (n x one dimensional) models. $J$. Fluid. Eng.-T. ASME, 125, 520-532.

14 C. Barba and C. Burkhardt, A phenomenological combustion model for heat release rate prediction in high-speed D.I. Diesel engines with common rail injection, SAE paper 200001-2933, 2000.

15 F. Chmela and G. Orthaber G., Rate of heat release prediction for direct injection Diesel engines based on purely mixing controlled combustion, SAE paper 1999-01-0186, 1999.

16 F. Chmela, M. Engelmayer, G. Pirker and A. Wimmer, Prediction of turbulence controlled combustion in Diesel engines, Proc. of THIESEL Conference, Valence, Spain, 2004.

17 A. Albrecht, J. Chauvin, F.-A. Lafossas, S. Potteau and G. Corde, Development of highly premixed combustion Diesel engine model: from simulation to control design, SAE paper 2006-01-1072, 2006.

18 F.-A. Lafossas, O. Colin, F. Le Berr and P. Menegazzi, Application of a New 1D Combustion Model to Gasoline Transient Engine Operation, SAE paper 2005-01-2107, 2005.

19 V. Talon, N. Venuti and P. Higelin, SI engine modeling using Bond Graph formalism, Proc. of ICE'03 Conference, Capri, Italy, 2003.
20 I.I. Wiebe, Brennverlauf und Kreisprozeb von Verbrennungsmotoren, in VEB-Verlag Technik, Berlin, 1970.

21 D.C. Karnopp, D.L. Margolis, and Rosenberg R.C., Systems dynamics : a unified approach, John Wiley \& Sons, NewYork, USA, 1990.

22 P. Ménégazzi, Ph. Aubret, F. Badin, R. Triguy and C. Marchand, An advanced simulation tool for consumption, emissions, and performance analysis of conventional and hybrid vehicles, FISITA paper F2006P115, 2006.

23 A. Ranini, S. Potteau and B. Gatellier, New developments of the NADI ${ }^{\mathrm{TM}}$ concept to improve operating range, exhaust emissions and noise. Proceedings of the THIESEL Conference, 2004.

24 R. Tilagone, and S. Venturi, Development of natural gas demonstrator based on an urban vehicle with a down-sized turbocharged engine, Which Fuels for Low $\mathrm{CO} 2$ Engines? IFP International Conference/Les Rencontres scientifiques de l'IFP, P. Duret, X. Montagne, Eds., pp. 145-155. Éditions Technip, Paris, 2004.

25 J. Chauvin, G. Corde, C. Vigild, N. Petit and P. Rouchon, Air path estimation on Diesel HCCI engine, SAE paper 2006-011085, 2006.

27 G. Le Solliec, F. Le Berr, G. Colin and G. Corde, Engine control of a downsized spark ignition Engine: from simulation to vehicle, E-COSM - Rencontres Scientifiques de l'IFP, October 2-4, 2006.

28 J.B. Heywood, Internal combustion engine fundamental, Mc Graw-Hill, New York, 1988.

29 P. Tona, P. Moulin, S. venturi, R. Tilagone and P. Gautier, Towards the integrated powertrain control of a mild-hybrid urban vehicle with a downsized turbo charged CNG engine, $E$ COSM - Rencontres Scientifiques de l'IFP, October 2-4, 2006.

Final manuscript received in October 2006

Copyright $@ 2007$ Institut français du pétrole

Permission to make digital or hard copies of part or all of this work for personal or classroom use is granted without fee provided that copies are not made or distributed for profit or commercial advantage and that copies bear this notice and the full citation on the first page. Copyrights for components of this work owned by others than IFP must be honored. Abstracting with credit is permitted. To copy otherwise, to republish, to post on servers, or to redistribute to lists, requires prior specific permission and/or a fee: Request permission from Documentation, Institut français du pétrole, fax. +33147527078 , or revueogst@ifp.fr. 